\title{
3 Wiederverwendete Inschriften: vom Umgang mit älteren Inschriften und Textmonumenten
}

Die Wiederverwendung älterer Objekte, Monumente und Bildwerke hat es in der römischen Welt zu allen Zeiten gegeben, und es wäre daher falsch, sie als ein exklusives Phänomen der Spätantike einzuordnen. Gleichwohl erfuhr die Praxis der Wiederverwendung am Ende der Antike eine derartig intensive Ausprägung, dass wir sie allemal als ein für diese Epoche charakteristisches und prägendes Phänomen bezeichnen können. Weder zur Zeit der Römischen Republik noch während der Kaiserzeit wurde für die Errichtung und Restaurierung von Bauwerken oder für die Aufstellung öffentlicher Denkmäler so oft auf bereits vorhandenes Material zurückgegriffen wie in der Spätantike. Nie zuvor setzte sich die Gesetzgebung so umfänglich und nachdrücklich mit dem Thema auseinander wie unter den Kaisern dieser Epoche. ${ }^{262}$ Und erst seit dem 4. Jh. können wir auch einen Diskurs über das Für und Wider abermals genutzter Monumente in den literarischen Quellen greifen, der im Übrigen von christlichen wie nicht-christlichen Autoren gleichermaßen geführt wurde. ${ }^{263}$

\subsection{Zur Einführung: Forschungspraktische Perspektiven und Stolperfallen}

Vor diesem Hintergrund wundert es nicht, dass sich insbesondere die Forschung zur Spätantike, allen voran auf den Gebieten der Kunstgeschichte und der Archäologie, mit dem Phänomen der Wiederverwendung beschäftigt und grundlegende Impulse gesetzt hat. Besonderes Interesse gilt seit jeher der Verwendung von Spolien, also von älteren erneut verwendeten Bauteilen wie Säulen, Kapitellen und Elementen der Bauplastik. ${ }^{264}$ Das wohl prominenteste Beispiel dieser Art stellt der Konstantinsbogen in Rom dar, für den Bau- und Dekorationselemente anderer Denkmäler aus der Zeit des Trajan, des Hadrian und des Commodus wiederverwendet und zum Teil umgearbeitet wurden. Das Neben- und Miteinander von Altem und Neuen an dem Bogen beschäf-

262 Die spätantiken Baugesetzgebungen sind vornehmlich in den beiden Gesetzessammlungen Codex Theodosianus (bes. Cod. Theod. 15, 1) und Codex Iustinianus überliefert; s. hierzu Geyer 1993 mit betonter Differenzierung zwischen westlicher und östlicher Baugesetzgebung; Liverani 2004, 411-430; Noethlichs 2013. - Zu den während der frühen und hohen Kaiserzeit erlassenen Bauverordnungen s. Geyer 1993, 66-69.

263 Zur Praxis der Wiederverwendung und deren Bewertung in den literarischen Quellen der Spätantike s. Coates-Stephens 2003 und Saradi 2011 mit einem Schwerpunkt auf wiederverwendete Statuen. 264 Wegweisend und grundlegend: Deichmann 1975; s. außerdem Ward-Perkins 1984, 203-229; Brenk 1987; Pensabene/Panella 1993/94; Alchermes 1994; Kinney 1997; Bouzek 2000 sowie die zuletzt erschienenen Sammelbände Jurković 2011 und Altekamp/Marcks-Jacobs/Seiler 2013 mit mehreren Beiträgen zu verschiedenen Aspekten.

Ә Open Access. () 2019 Katharina Bolle, publiziert von De Gruyter. (c) BY-NC-ND Dieses Werk ist lizenziert unter der Creative Commons Attribution-NonCommercial-NoDerivatives 4.0 Lizenz. 
tigt die Forschung bis heute, und nach wie vor herrscht keine Einigkeit darüber, wie weit man bei der Bewertung dieses und ähnlicher Denkmäler gehen darf: War die Verwendung von Spolien vornehmlich pragmatischen Gründen geschuldet oder folgte sie konzeptuellen und programmatischen Überlegungen? Drückte sich in dem Rückgriff auf Denkmäler der Vergangenheit der Wunsch nach ideologisch gefärbten Botschaften aus? Wie sind diese zu deuten? Und inwiefern war es dem Betrachter überhaupt möglich, das Gesehene in diesem Sinn zu erkennen und zu verstehen? ${ }^{265}$ Es sind dies Fragen, die sich nicht nur bei der Beschäftigung mit wiederverwendetem Material im Kontext von Architektur und Bildkunst stellen. Auch wenn es um den Umgang mit älteren Inschriften und den dazugehörigen Monumenten, um deren Aneignung, erneute Nutzung, Umgestaltung und Neuerrichtung geht, spielen die möglichen Motivationsgründe und Intentionen dahinter eine entscheidende Rolle für die Beurteilung solcher Objekte und für das Verständnis der menschlichen Protagonisten. Im Fall von wiederverwendeten Inschriften - nennen wir sie in unserem Zusammenhang ,Inschriftenspolien' - müssen wir neben den zugrundeliegenden Absichten der Auftraggeber und Initiatoren noch eine Reihe weiterer Aspekte berücksichtigen, welche sich aus dem hybriden Wesen von Inschriften zwischen Monument und Text ergeben. So ist es nämlich oftmals nicht einfach zu entscheiden, ob der Inschriftenträger oder tatsächlich die Inschrift selbst, das heißt der Text Gegenstand der Wiederverwendung war, ob man sich des Monuments also vorrangig mit Blick auf seine materiellen Eigenschaften, etwa als einfach zu beschaffendes Baumaterial, bediente oder ob man es auf den darauf angebrachten Text abgesehen hatte. Und selbst wenn dieser im Kontext der neuen Verwendung nach wie vor sichtbar und lesbar war, musste dies keineswegs bedeuten, dass man die Inschrift absichtsvoll zur Schau stellen und wahrgenommen wissen wollte. Womöglich stand man ihr auch eher gleichgültig gegenüber, hatte sie als obligaten Teil des betreffenden Stücks in Kauf genommen oder aber durch einen heute verlorenen Farb- oder Putzauftrag unkenntlich gemacht. Für die Beantwortung der Frage, wie relevant der Text für die Wiederverwendung eines inschriftlichen Monuments tatsächlich war, muss dessen fortwährende Sichtbarkeit also kein eindeutiges Kriterium sein (ebenso wenig übrigens, wie es die eingeschränkte oder gar entzogene Sichtbarkeit sein muss ${ }^{266}$ ).

Diesen Gedanken sollten wir stets im Gedächtnis behalten, und zwar umso mehr, wenn wir uns unserer speziellen Rolle als moderner Betrachter erinnern und uns bewusst machen, dass unser Blick auf die Objekte vor allem von wissenschaftlicher Neugier getrieben ist und sich damit fundamental von demjenigen der Zeitgenossen

265 L’Orange 1939; Ross Holloway 1985; Koeppel 1986; Ward-Perkins 1999, 227-233. Eine Zusammenfassung der zentralen Thesen und wichtigsten Argumente in dieser Debatte findet sich bei Liverani 2004 und Sande 2012; s. hierzu auch den Beitrag zu Spolien in spätantiken Stadtmauern von H. Dey, der in diesem Zusammenhang von den zwei Schulen der „negative spolia“ und „positive spolia“ spricht: Dey 2012, 291-294.

266 S. hierzu Kap. 5.5. 
unterscheidet. Während wir uns für die Objekte ja gerade wegen der darauf angebrachten Inschriften interessieren und uns ganz auf diese fokussieren, mochten sie für die Zeitgenossen der Spätantike belanglos und für die Wiederverwendung des jeweiligen Stücks ohne Bedeutung gewesen sein - und dies war unter Umständen viel öfter der Fall als es uns lieb ist, neigen wir in unserem Forschungsdrang doch dazu, den Texten größeren Stellenwert beizumessen als ihnen tatsächlich zuteil wurde.

Bevor wir also nach möglichen Motiven für die Wiederverwendung einer Inschrift fragen können, gilt es zunächst zu klären, ob wir es mit einem wiederverwendeten Inschriftenträger oder einer wiederverwendeten Inschrift zu tun haben - wobei beide Fälle gleichermaßen interessant sind, gewähren sie doch jeweils auf ihre eigene Art Einblick in den Umgang mit und die Wertschätzung von älteren Textmonumenten in der Spätantike. Denn selbst wenn ein inschriftliches Monument aus rein pragmatischen Gründen wiederverwendet wurde - beispielsweise eine Statuenbasis für den Bau einer Mauer oder eine Grabplatte für die Pflasterung eines Bodens -, so musste man gegenüber dem darauf angebrachten Text doch irgendeine Haltung eingenommen haben, und sei es, dass man ihn ignorierte. Stand man der Beschriftung indes nicht vollkommen gleichgültig gegenüber, so gab es eine Vielzahl an Möglichkeiten, ihr zu begegnen und mit ihr zu verfahren: Man konnte sie kaschieren, indem man sie übermalte, mit Putz verkleidete oder den Inschriftenträger so positionierte, dass die Schrift nicht mehr zu sehen war. Man konnte sie eliminieren, indem man den Text ganz oder teilweise ausmeißelte. Man konnte die alte Inschrift in einen neu angebrachten Text integrieren. Man konnte sie modifizieren. Und schließlich konnte man sie auch inszenieren und so zum eigentlichen Gegenstand des neu errichteten Denkmals machen.

Es liegt in der Natur der Sache, dass mit jedweder Form der Wiederverwendung eines Objekts Veränderungen einhergingen, die sowohl dessen äußere Gestalt als auch räumliche Präsenz betrafen. Insbesondere für Bauprojekte wiederverwendete Stücke wurden häufig ihrer neuen Bestimmung entsprechend bearbeitet, behauen und zurechtgeschnitten. Aber auch wenn die ursprüngliche Funktion beibehalten wurde, etwa im Fall eines neu beschrifteten Meilensteins, blieb das jeweilige Monument doch nicht vollkommen unverändert. Oftmals wurde der alte Text entfernt oder unkenntlich gemacht. Gleiches gilt für den räumlichen Kontext, der nur in den seltensten Fällen der gleiche blieb. In der Regel wurde das betreffende Monument aus seinem ursprünglichen Kontext herausgelöst und in einen neuen überführt, das eine Mal einhergehend mit einem Wandel seiner eigentlichen Funktion, wie etwa bei einer als Pflasterstein wiederverwendeten Grabplatte, das andere Mal unter deren Beibehaltung, beispielsweise im Fall einer noch einmal genutzten Basis, die im Zug ihrer neuerlichen Verwendung als Statuenpostament von einem Ort der Stadt an einen anderen verbracht wurde. Es ist nicht zuletzt diese oftmals ganz offenkundige Transformation von Gestalt und Kontext, die uns eine Inschrift bzw. ein inschriftliches Monument erst als ein wiederverwendetes solches zu erkennen gibt. 
Jede Auseinandersetzung mit dem Thema ,Inschriftlichkeit und Wiederverwendung، verlangt also danach, viele unterschiedliche Aspekte zu berücksichtigen, die in der Frage nach dem konkreten Gegenstand der Wiederverwendung (Was?), dem Modus (Wie?), dem Zweck (Wozu?), dem Kontext (Wo?), der Zeit (Wann?) und dem Beweggrund der Akteure (Warum?) ihre forschungspraktische Ausformulierung finden. In welchen verschiedenen Dimensionen und Spielarten sich die Wiederverwendung von Inschriften und Textmonumenten Ausdruck verschaffte, soll nun anhand einiger ausgewählter Fallbeispiele vor Augen geführt werden. Zuvor sei das Phänomen Wiederverwendung in einem allgemeineren Sinn und umfassenderen Zusammenhang zur Sprache gebracht, und zwar vor dem Hintergrund der kaiserlichen Gesetzgebung und des gesellschaftlichen Diskurses, wie er vor allem durch schriftliche, aber auch einige epigraphische Quellen greifbar wird.

\subsection{Zum Hintergrund: Wiederverwendung in der kaiserlichen Gesetzgebung und im öffentlichen Diskurs}

Wie eingangs angedeutet, gab die Sitte, auf ältere Monumente zurückzugreifen und sich ihrer für die eigenen Zwecke zu bedienen, erst in der Spätantike Anlass zu ernsthaften staatlichen Regulierungen und öffentlichen Auseinandersetzungen. Offenbar wurde nun derart häufig wiederverwendet, dass sich einerseits die Kaiser dazu veranlasst sahen, die Wiederverwendung durch Gesetze und Strafandrohungen in geordnete Bahnen zu lenken, und dass sich andererseits Schriftsteller des Themas annahmen und dieses in ihren Werken thematisierten. Bezeichnenderweise ist sowohl in den Rechtstexten als auch in den literarischen Quellen nur in seltenen Ausnahmefällen dezidiert von der Wiederverwendung älterer Inschriften oder von mit solchen versehenen Monumenten die Rede. Wir müssen daher davon ausgehen, dass solcherlei Stücke keinesfalls als selbständige ,Kategorie“ wahrgenommen wurden (zumal die meisten öffentlichen Denkmäler und Gebäude ohnehin mit Inschriften ausgestattet waren), für die gesonderte juristische Regularien hätten geschaffen werden müssen und deren Nachleben die Zeitgenossen zu einer eigenen Debatte angeregt hätte. ${ }^{267}$ Gleichwohl lässt sich der spezifische Umgang mit älteren Inschriften in der Spätantike kaum hinreichend erklären, ohne die rechtlichen und normativen Rahmenbedingungen dieser Zeit wenigstens kurz zu umreißen.

Erste Hinweise auf die gesellschaftliche Relevanz des Themas sind in der 2. Hälfte des 4. Jhs. auszumachen. Im Codex Theodosianus und den spätantiken Digesten sind

267 In den Rechtstexten wird m. W. nur ein einziges Mal auf bereits bestehende Inschriften Bezug genommen: Mit dem Erlass Dig. 50, 10, 7 sollte sichergestellt werden, dass eine Bauinschrift mit dem Namen des ersten Stifters eines öffentlichen Gebäudes auch nach einer späteren Restaurierung durch einen Zweiten nicht entfernt werden durfte. In den literarischen Texten wird die Wiederverwendung von Inschriften indes nicht thematisiert. 
mehrere Gesetze und constitutiones überliefert, die den Umgang mit altem Baubestand zu regeln versuchten. So war es etwa unter Geldstrafe verboten, Baumaterial öffentlicher Gebäude für die Errichtung oder Renovierung von Privateigentum wiederzuwenden oder von einer Stadt in eine andere zu überführen, um so zu verhindern, dass eine Gemeinde ihres altehrwürdigen öffentlichen Schmuckes (decus) beraubt würde. ${ }^{268}$ Grundsätzlich sollte es gelten, Altes zu bewahren und gegebenenfalls zu renovieren, anstatt es für die Errichtung von Neuem zu benutzen. ${ }^{269}$ Sicherlich waren diese Regularien auf der einen Seite Ausdruck pragmatischer und ökonomischer Überlegungen und zielten nicht zuletzt darauf ab, die kaiserliche und die städtischen Kassen zu schonen - für die Renovierung öffentlicher Gebäude durfte man nämlich sehr wohl auf bereits bestehendes Material zurückgreifen. ${ }^{270}$ Auf der anderen Seite lassen die Gesetzestexte aber auch erkennen, dass man tatsächlich um das gemeinsame Kulturgut und das repräsentative Stadtbild der Gemeinden besorgt war, ist von den öffentlichen Bauten doch als decus, ornamentum, splendor publicus oder ornatus civitatis die Rede. ${ }^{271}$

Womöglich waren die Gesetze auch direkte Reaktionen auf städtische Unruhen und Protestbewegungen seitens der Bürgerschaften, die sich angesichts des allzu rücksichtslosen Verhaltens staatlicher Magistrate und vermeintlicher Wohltäter ihres gemeinschaftlichen Baubestands und historischen Erbes beraubt sahen. ${ }^{272}$ So berichtet etwa Ammianus Marcellinus, dass der römische Stadtpräfekt des Jahrs 398, Lampadius, den Zorn der Bevölkerung auf sich zog, weil er für Neubauten und Renovierungen zahlreiche ältere Gebäude der Stadt berauben ließ, ohne dafür zu zahlen. ${ }^{273}$ Von Johannes von Antiochia wissen wir, dass es im Jahr $456 \mathrm{zu}$ einem heftigen Aufstand in Rom kam, nachdem Kaiser Avitus wertvolle Bronzen von öffentlichen Gebäuden hatte entfernen und an Händler verkaufen lassen, um mit dem Erlös seine Soldaten zu bezahlen. ${ }^{274}$ Dass der Rückgriff auf öffentliches Gut und dessen Wiederverwendung selbst durch staatliche Beamte und zugunsten der Gemeinschaften keineswegs immer gutgeheißen wurde, belegt auch die Ehreninschrift für den consularis der Provinz Campania, Barbarius Pompeianus, aus dem Jahr 333. Darin wird ausdrücklich betont, dass dieser für die Pflasterung der Straßen von Abella ausschließlich aus dem Gebirge

268 Cod. Theod. 15, 1, 1 (357 unter Constantius II.); 15, 1, 37 (398 unter Valentinian II. und Theodosius II.); Cod. Iust. 8, 10, 6. Für Bau- und Reparaturmaßnahmen an gemeinschaftlich genutzten öffentlichen Gebäuden durfte allerdings sehr wohl auf alten Baubestand zurückgegriffen werden: Dig. 30, 41, 5; 39, 2, 48.

269 Cod. Theod. 15, 1, 11; 15; 16; 19; 21; 28; 37; 41; 43; Cod. Iust. 8, $10,8$.

270 Nov. Maj. 4.

271 Cod. Theod. 15, 1, 16; 25; 37; 41; 43; Dig. 30, 32, 2; 30, 122. Noch stärker wird dies in einer Novelle des Jahrs 458 unter Majorian deutlich: Nov. Maj. 4.

272 Vgl. Coates-Stephens 2003, 352f.

273 Amm. 27, 4, 8-10.

274 Jo. Ant. frg. 225, 1 (ed. Mariev 2008). 
gewonnene Steine verwendet und sich dafür nicht an verfallenen(!) Gebäuden des Städtchens bedient hatte. ${ }^{275}$

Weniger aus moralischen Gründen als vielmehr aufgrund ästhetischer Anschauung mokierte sich der griechische Kirchenhistoriker Socrates Scholasticus im frühen 5. Jh. über die Stadtmauer von Chalkedon am Bosporus, in der auch hundert Jahre nach deren Reparatur noch immer die hierzu wiederverwendeten Blöcke und Spolien zu erkennen gewesen seien, welche das schöne Gesamtbild des zyklopischen Mauerwerks geradezu verschandelt hätten. ${ }^{276}$

Erst im späteren 5. und 6. Jh. wurden positive Stimmen lauter, die sich durchaus wohlwollend gegenüber der Praxis der Wiederverwendung äußerten. Am deutlichsten ist dies in den von Cassiodor redigierten Briefen des Theoderich nachzulesen, in denen die Verwendung von Spolien durch den Gotenkönig keineswegs als Raub am römischen Kulturgut ausgelegt wurde, sondern im Gegenteil als Bewahrung des alten Baubestands und ostentative Würdigung der römischen Vergangenheit, „damit wir sowohl das von den Alten Geschaffene vom Verfall behüten und erneuern als auch das Neue mit dem Glanz der guten alten Zeit bekleiden“, so der König in einem Schreiben an den damaligen Stadtpräfekten von Rom. Mit dieser Strategie des Bewahrens und Erneuerns suchte Theoderich einerseits, sich als legitimen Nachfolger der römischen Kaiser zu empfehlen und andererseits deren Ruhm als Bauherren teilhaftig zu werden. Baupolitik war hier also durchaus ein zentraler Faktor der ihm eigenen Herrschaftslegitimation. ${ }^{277}$

Neben der erneuten Nutzung architektonischer Elemente öffentlicher Baudenkmäler erregte insbesondere die Plünderung von Grabmälern die Gemüter, sodass Constantius II. 356 ein Gesetz zum Schutz von Begräbnisstätten und deren Ausstattung erließ. ${ }^{278}$ Baumaterial aus Gräbern zu gewinnen sei gleich auf zweifache Weise frevelhaft, so die Begründung. Einerseits entweihe man so die letzte Ruhestätte der Toten, andererseits verunreinige man die Sphäre der Lebenden, indem man das unrechtmäßig erworbene Material in ihre Welt überführe, wo es nicht hingehöre. Interessanterweise kam es unter Valentinian III. 447 zu einer Neuauflage des Gesetzes, welche sich nunmehr ausdrücklich an Mitglieder des Klerus richtete, unter denen die Sitte der Wiederverwendung von Grabdenkmälern für christliche Kultanlagen offenbar besonders weit verbreitet war. ${ }^{279}$ Und tatsächlich finden sich in vielen frühchristlichen

275 CIL X 1199 = ILS 5510: [Pompe]iani / Barbarus Pompeian(us) / v(ir) c(larissimus) cons(ularis) Kamp (aniae) civita/tem [A]bellam nuda ante / soli deformitate sorden/tem silicibus e montibus / excisis non e dirutis / monumentis advec/tis consternendam / ornandamque cura/vit / cur[ante ---] Pro/culo patrono et cur(atore) / Abellanorum.

276 Socr. Schol. 4, 8. - Zur ästhetischen Dimension des spätantiken Bauwesens s. Geyer 1993.

277 Cassiod. var. 7, 5, 3; 7, 15, 1, Übersetzung nach P. Dinzelbacher in: Janus 2010, 76. - Zur Kulturpolitik Theoderichs mit speziellem Blick auf dessen Umgang mit dem kulturellen Erbe der römischen Vergangenheit s. Brenk 1987, 107-109; Geyer 1993, 63-65; Coates-Stephens 2003, $355 f$.

278 Cod. Theod. 9, 17, 4.

279 Nov. Val. 23. 


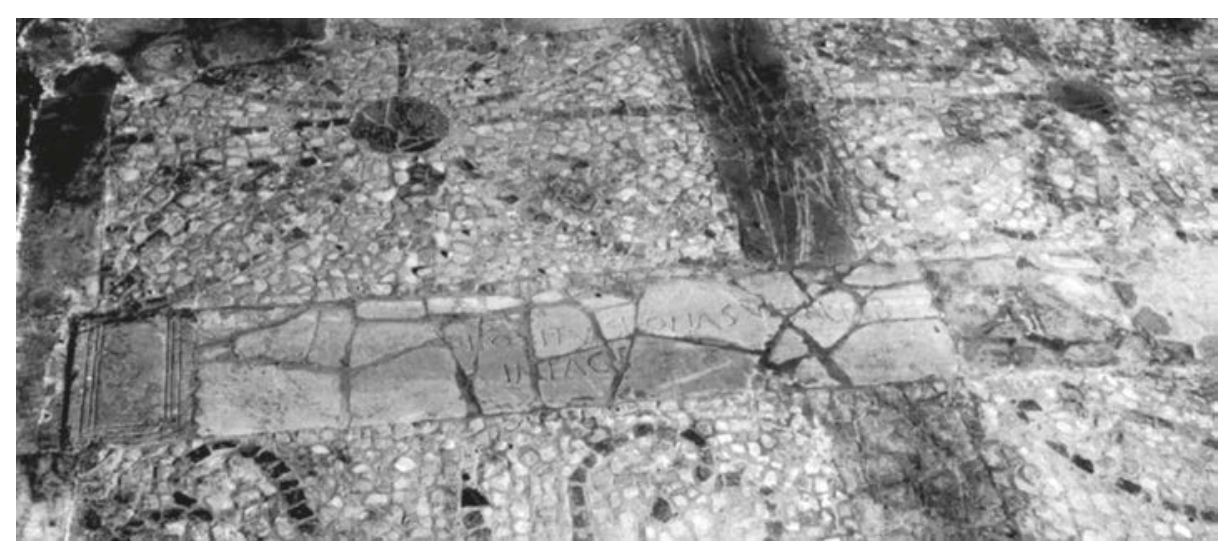

Abb. 21: Wiederverwendete Grabinschrift im Bodenbelag von S. Clemente in Rom.

Kirchen des 5. und 6. Jhs. immer wieder als Baumaterial oder Pflastersteine zweckentfremdete Grabplatten und Epitaphe, deren darauf angebrachte Inschriften zum Teil durchaus sichtbar und lesbar waren, wie etwa im Fall einer ehemaligen Loculusplatte mit der Grabinschrift eines gewissen Leonas in der Basilika S. Clemente in Rom, die beim Ausbau der Kirche im späteren 6. Jh. als Rahmenelement für die Mosaikfelder im Boden eingesetzt wurde (Abb.21). ${ }^{280}$

Zahlreich waren auch die in der Basilika Alt St. Peter verbauten Inschriftenspolien, darunter Tafeln, Basen und Architekturelemente aus der Zeit des Titus, des Trajan und des Gallienus. ${ }^{281}$ Selbst für die Memorie des heiligen Petrus hatte man auf eine alte Grabinschrift aus dem 2. Jh. zurückgegriffen: Beim Ausbau des kleinen Grabhauses im 4. Jh. nutzte man die eigentlich dem Gedenken an den Freigelassenen P. Aelius Isodorus angedachte Marmortafel, um den unterirdischen Hohlraum der Petrusmemorie abzudecken. ${ }^{282}$ Es sind Befunde wie diese, die nicht nur bestätigen, dass Gräber tatsächlich rechtlichen Schutzes bedurften, sondern auch nahelegen, dass die entsprechenden Gesetze ihre Wirkung oftmals verfehlten. Denn offenbar konnten weder staatliche Strafandrohungen noch moralische Bedenken noch der Vorwurf ästhetischer Verfehlung die Zeitgenossen davon abhalten, älterer Bau-, Kunst- und Grabdenkmäler habhaft zu werden und für die eigenen Zwecke zu verwenden. Wie dies konkret vonstatten gehen konnte und welche verschiedenen Motivationen und Absichten damit verbunden waren, soll nun anhand konkreter Beispiele spätantiker Inschriftenspolien vor Augen geführt werden. Dabei soll vor allem die Frage im Mittelpunkt stehen, warum man ausgerechnet dieses oder jenes Stück für eine erneute Nutzung auswählte und welche Vorteile es gegenüber neu geschaffenem Material bot: Was war das Alte im Stande zu leisten, was das Neue nicht vermochte?

280 ICUR I 231; Guidobaldi/Guidobaldi 1983, $400 f$.

281 Lanciani 1925, 96-98.

282 Thümmel 1999, 63. 


\subsection{Wiederverwendung in andersartigen Kontexten: Inschriftenspolien als Baumaterial}

Ohne Zweifel bilden die aus pragmatischen oder ökonomischen Gründen als Baumaterial wiederverwendeten tituli die größte Gruppe spätantiker Inschriftenspolien. Besonders begehrt waren Statuenbasen, Altäre oder Gebälkteile, die sich wegen ihrer quaderartigen Gestalt gut für Fundamentlegungen und die Errichtung von Mauerwänden verwerten ließen, so geschehen etwa in Classe bei Ravenna, wo man eine monumentale, ehemals in Bronzelettern ausgeführte Architravinschrift mit dem Namen des Divus Iulius als Schwelle für ein Gebäude des 5. Jhs. in Anspruch nahm. ${ }^{283}$ Vor allem in den Fundamenten spätantiker Stadtmauern des späteren 3. bis 6. Jhs. sind derlei Stücke in großer Zahl zu finden. Sie wurden dort zusammen mit Meilensteinen, Architekturfragmenten und Sarkophagen als taugliche Spolien vermauert. Exemplare dieser Art sind allenthalben sowohl in der westlichen wie in der östlichen Reichshälfte, insbesondere aber in Gallien zu finden. ${ }^{284}$ Aus dem italischen Raum ließen sich etwa die Befestigungsanlagen der istrischen Hafenstadt Pula exemplarisch anführen, die zwischen dem 4. und 6. Jh. immer wieder verstärkt wurden. Dabei kamen auch etliche Monumente aus dem Stadtgebiet und den nahe gelegenen Nekropolen an den Rändern der Gemeinde zum Einsatz, die sowohl in den Fundamenten und den unteren Teilen der Stadtmauern als auch in den oberen Abschnitten verbaut wurden. ${ }^{285}$ Darunter waren neben Architekturelementen, Säulentrommeln und Stelen auch viele Grabaltäre und Inschriftentafeln (Abb. 22).

Die Stücke wurden offenbar ohne sorgfältige Planung verbaut; jedenfalls waren nur die wenigsten im Vorfeld eigens bearbeitet und behauen worden und wurden allenfalls grob gebrochen. Beim Versatz der Stücke scheint man auch keinerlei Rücksicht auf darauf angebrachte Reliefs oder Inschriften genommen zu haben, die das eine Mal nach innen, das andere Mal nach außen versetzt, hier auf dem Kopf und da querliegend vermauert wurden. Offensichtlich galt das Interesse hier in erster Linie den Monumenten in ihrer Eigenschaft als Baumaterial.

Einen ähnlichen Anblick bieten auch andere spätantike Stadtmauern norditalischer Gemeinden, welche im Zeitraum zwischen dem 4. und 6. Jh. ihre Befestigungsanlagen ausbauten, erweiterten und mitunter verstärkten. Beobachten lässt sich dies

283 Vgl. Susini 1990, 133.

284 Eine Studie zu Spolien in Stadtmauern des späten 3. Jhs. in Gallien bietet Dey 2012; mit Blick auf Britannien, Gallien und Germanien: Blagg 1983; für den griechischen Raum s. Frey 2006; für die östliche Reichshälfte in byzantinischer Zeit s. Greenhalgh 1999. - Es ist auffällig, dass sich regional stark unterschiedliche Traditionen ausgeformt haben. So kamen beispielsweise in Hispanien und Gallien vornehmlich Spolien aus sepulkralen Kontexten zum Einsatz, von denen man in Britannien hingegen nur in seltenen Ausnahmefällen Gebrauch machte und häufiger auf Bauglieder profaner Gebäude zurückgegriff.

285 Vgl. hierzu Girardi-Jurkić 2011, 25. 


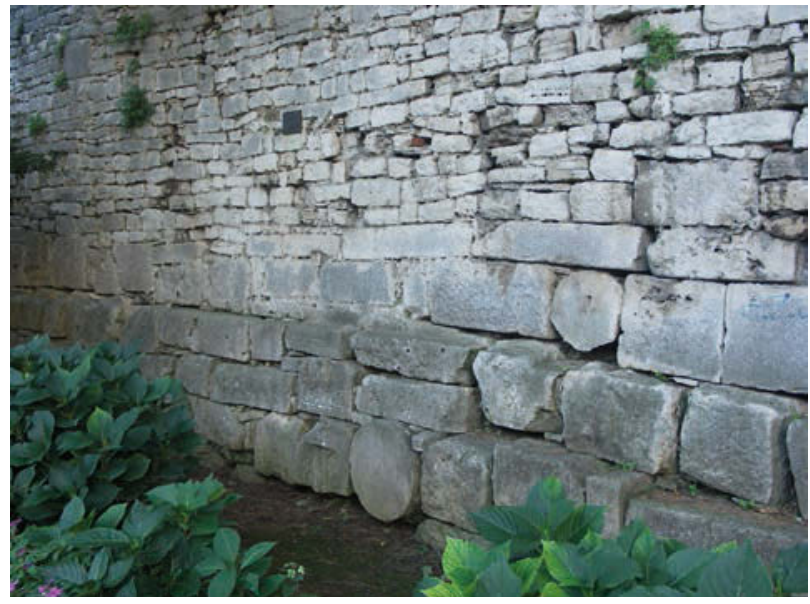

Abb. 22: Fundament der spätantiken Stadtmauern von Pola mit darin verbauten Spolien.

etwa in Aquileia, ${ }^{286}$ Brixia, ${ }^{287}$ oder Comum. ${ }^{288}$ Und in Mediolanum griff man für den unter Maximian errichteten spätantiken Mauerring sogar auf eine Statuenbasis für ein zu seinen Ehren errichtetes Standbild zurück. ${ }^{289}$ Die Forschung hat insbesondere angesichts der massiven Verwendung von Spolien lange Zeit angenommen, dass die vor allem in Gallien und Norditalien zu beobachtenden Verstärkungen und Erneuerungen der Stadtmauern auf Bedrohungen von außen, wie etwa feindliche Einfälle von Germanen oder Goten, zurückzuführen sei. Nicht zuletzt weil die archäologischen Befunde aber in den wenigsten Fällen darauf hindeuten, dass die Mauern in großer Eile errichtet worden wären, führt man mittlerweile andere Erklärungen ins Feld, bei denen die Wiederverwendung von Spolien stärker als kulturelle Praxis denn als Verlegenheitslösung verstanden wird. So war die verstärkte Sorge um die Stadtmauern in der Spätantike wohl eher dem städtischen Repräsentationsbedürfnis als einer vermeintlichen Bedrohung geschuldet: Die Stadtmauern dienten als Symbol städtischen Prestiges und galten als repräsentative Leistung der jeweiligen Stadt. Der Rückgriff auf ältere Monumente und deren zum Teil sichtbare Eingliederung in die Stadtmauern ist vor diesem Hintergrund also eher als eine Facette des Gesamtphänomens Wiederverwendung zu begreifen und weniger als schnelle Notlösung vor drohender Gefahr. ${ }^{290}$

286 Spolien aller Art finden sich in der spätantiken Stadtmauer des späten 4./frühen 5. Jhs., in der Mauer südlich der Forumsbasilika und in der sog. theodosianischen Mauer. In letzterer wurde u. a. eine Inschrift der Kaiser Valentinian II., Theodosius und Arcadius verbaut; vgl. Haug 2003, $328 \mathrm{f}$.

287 Haug 2003, 384.

288 Maggi 1993.

289 CIL V 5807 = 5808. Ob die um 300 zur Aufstellung gekommene Basis für Maximian tatsächlich schon während der ersten Bauphase der spätantiken Mauer, und damit unmittelbar nach der Errichtung der Ehrenstatue, zum Einsatz kam, ist allerdings unklar. Möglicherweise wurde sie auch erst für eine nachträgliche Reparatur nach der Zeit Maximians wiederverwendet; vgl. hierzu Ceresa Mori 1993, 23; Haug 2003, 416.

290 Vgl. hierzu Witschel 2012/13 [2015], 33f. 
Neben beschrifteten Basen wurden auch Inschriftentafeln aller Art und Loculusplatten zu Dutzenden wiederverwendet. Derlei Stücke kamen wegen ihrer handlichen Größe, der flachen, flächigen Form und der glatten Oberfläche vornehmlich als Pflastersteine zum Einsatz und haben als solche im Boden vieler öffentlicher wie privater Gebäude eine neue Bestimmung gefunden. Ein bekanntes Beispiel ist die für die spätantike Neupflasterung des Comitiums in Rom wiederverwendete Inschriftentafel aus sullanischer Zeit, welche einst die Durchführung von Bauarbeiten an öffentlichen Straßen in der Stadt dokumentierte. ${ }^{291}$ Nach einem verheerenden Brand im Jahr 283 bediente man sich ihrer für die nötig gewordenen Reparaturarbeiten, zerschnitt sie ihrer neuen Funktion entsprechend in Stücke und verlegte diese mit der Schriftseite nach unten in den Boden zu Füßen des Septimius-Severus-Bogens. ${ }^{292}$ Dass man für die Baumaßnahmen am Pflaster ausgerechnet auf ein Textdokument zurückgriff, das seinerzeit selbst anlässlich eines Straßenausbaus geschaffen worden war, mag ironische Züge tragen, lässt sich aber wohl kaum als absichtsvolle Auswahl interpretieren. Viel eher müssen wir davon ausgehen, dass allein pragmatische Überlegungen zum Tragen gekommen waren, und dass die Tafel nicht wegen der darauf angebrachten Inschrift, sondern aufgrund ihrer guten Eignung als Pflasterstein ausgesucht worden war. ${ }^{293}$ Gleiches gilt für die zahlreichen in spätantiken Wohnhäusern wiederverwendeten Inschriftentafeln. Darunter finden sich mitunter sogar Exemplare, die einst auf kaiserliche Initiative hin errichtet wurden, wie etwa diejenige in einer domus unter der Via Nazionale in Rom zum Vorschein gekommene Restaurierungsinschrift der Acqua Virgo mit dem Namen Konstantins I. ${ }^{294}$

Sehr häufig verwendete man auch Grabinschriften der römischen Kaiserzeit als Baumaterial wieder. Beispiele bieten eine domus auf dem Esquilin, ${ }^{295}$ eine weitere auf dem Aventin ${ }^{296}$ sowie eine villa unter der heutigen Piazza Venezia. ${ }^{297}$ Wie im Fall der konstantinischen Bauinschrift von der Acqua Virgo waren auch hier weder der ursprüngliche Kontext der Inschriften noch ihre eigentliche Funktion von Bedeutung - einst am Grab errichtet, um das Andenken an den Verstorbenen zu bewahren, dienten sie nun ,weltlichen‘ Zwecken und hatten jegliche sakrale Aura verloren. Die jeweiligen Hausherren scheint dies jedoch kaum gekümmert zu haben. Angesichts der kaiserlichen Rechtserlasse des 4. und 5. Jhs., wonach die Plünderung einer Grabstätte und die Wiederverwendung des geraubten Materials ein Akt größten Frevels gegen-

291 CIL VI 37043 = AE 1899, 144, 145 .

292 Lanciani 1988, $250 \mathrm{f}$.

293 Ein ähnliches Beispiel hält das Forum von Aquileia bereit, in das eine Votivtafel des 2. oder 3. Jhs. mit der Schriftseite nach oben eingelassen wurde; s. hierzu Maselli Scotti/Zaccaria 1998, 155-157 mit Abbildung.

294 CIL VI 31564; Lanciani, in: NSc 1881, 319f.; ders., in: BCAR 10, 1881, 19; zuletzt Machado 2012, $149 \mathrm{f}$.

295 BCAR 14, 1886, 196-198.

296 BCAR 21, 1893, 8.

297 BCAR 30, 1902, $287 f$. 
über den Toten wie den Lebenden war, hatten sie etwaige Strafen oder moralische Gewissensbisse sogar durchaus billigend in Kauf genommen, wenn sie die der jenseitigen Sphäre entstammenden Inschriften in ihren privaten Wohnhäusern für derartig profane Zwecke nutzten. Sie verwendeten die Stücke also nicht wegen, sondern nachgerade trot $z$ ihrer Eigenschaft als Inschrift wieder.

Wie weit ursprüngliche und neuerliche Funktion wiederverwendeter Inschriften auseinanderklaffen konnte, zeigt sich in aller Deutlichkeit an einem Befund aus dem spätantiken Ostia: Dort fungierten Grabinschriften des 2. Jhs. als Toilettensitze in einer öffentlichen Latrine. ${ }^{298}$ Ähnliche Diskrepanzen sind aber auch umgekehrt zu beobachten: Um eine Grablege in der Cyriacus-Katakombe in Rom zu schließen und sie mit dem Namen des hier bestatteten Christen zu versehen, wählte man eine Marmortafel, die angesichts der darauf angebrachten Spielfelder auf der Rückseite zuvor als tabula lusoria - und damit einem reichlich weltlichen Vergnügen - gedient hatte. ${ }^{299}$

Bei allen diesen Beispielen fällt es nicht schwer, sich die zugrundeliegenden Intentionen der Bauherren und Hinterbliebenen vorzustellen: Ihr Interesse an den verwendeten Stücken war deren materiellen Eigenschaften geschuldet, welche sie als Baumaterial für eine Mauer, ein Fundament, eine Pflasterung oder eben einen Toilettensitz prädestinierten: steinerne Stofflichkeit, blockartige bzw. flache Gestalt, formale und materielle Beständigkeit, leichte Handhabbarkeit. Und nicht zuletzt mochte auch die geriffelte Oberflächenstruktur der mit dem Meißel bearbeitetet Steine ausschlaggebend gewesen sein, die sich besonders gut für den Auftrag von Putz anbot, weshalb Bauleute sie anderen Spolien manches Mal vorgezogen haben könnten. ${ }^{300}$ Vermutlich waren die betreffenden Stücke auch leichter und kostengünstiger zu beschaffen als neues Baumaterial, stammten womöglich aus dem Fundus eines eigens für solche Zwecke eingerichteten Depots mit Architekturelementen verfallener Bauten und ausgedienten Denkmälern, die sowohl für öffentliche Bauvorhaben genutzt als auch an private Kunden verkauft wurden. Waren solche Lager im 3. und 4. Jh. noch vergleichsweise selten und in ihrem Angebot relativ beschränkt, boten im 5. Jh., als öffentliche Gebäude und Plätze zunehmend sich selbst überlassen wurden und verfielen, offenbar mehr und mehr Händler Spolien zum Verkauf an. Depots und Magazine mit kaiserzeitlichen Spolien aller Art sind etwa aus Rom und Ostia bekannt. ${ }^{301}$ Dank der intensi-

\footnotetext{
298 Meiggs 1960, 143

299 BCAR 16, 1888, $175 \mathrm{f}$.

300 Vgl. Coates-Stephens 2002, 289 mit Anm.16.

301 S. Pensabene 2004 zu Rom; Gering 2017 zu Ostia. Offenbar muss es auch in Sagalassos solche Depots gegeben haben, die bisher allerdings noch nicht ausgewertet sind, vgl. Gering 2017, 164 Anm. 29. $\mathrm{Zu}$ den in solchen Depots gelagerten Stücken zählten auch viele Spolien aus römischen Kultanlagen und Heiligtümern. Dass das von dort stammende Material besonders häufig Gegenstand einer späteren Wiederverwendung wurde, ist aber nicht zwangsläufig darauf zurückzuführen, dass die den römischen Göttern geweihten Tempel im Zuge der staatlichen Privilegierung des Christentums nach Konstantin I. religiösen Eiferern und deren Zerstörungswut zum Opfer fielen. Es war wohl eher so, dass diese Bauten angesichts der fortschreitenden Christianisierung und spätestens nach ihrer offizi-
} 
ven Grabungsarbeiten Axel Gerings ist der Befund in Ostia besonders anschaulich: ${ }^{302}$ Anhand von großen Mengen Marmorabschlags und mitunter gut sortierten Anhäufungen von Spolienmaterial konnten mehrere steinverarbeitende Werkstätten rund um das Forum identifiziert werden, die hier seit der Mitte des 5. Jhs. bis zur Entvölkerung des Stadtzentrums im 6. Jh. tätig waren. In ihnen wurden sowohl alte Monumente zu Baumaterial wie Bodenplatten zersägt als auch neue Dekorelemente geschaffen, die womöglich nicht nur für den Bau lokaler Kirchenanlagen im Territorium von Ostia, sondern auch für stadtrömische Bauprojekte genutzt wurden. Einige dieser Werkstätten boten ihre Stücke eventuell direkt in angeschlossenen Ladenräumen zum Verkauf an. Ausreichende Nachfrage war im Übrigen durchaus gegeben. Im privaten Bereich kam es vor allem in den bevölkerungsreichen Metropolen immer noch zu Neubauten großer Stadthäuser und in den ländlicheren Gebieten zu teils luxuriösen Landvillen. ${ }^{303}$ Ungleich bedeutender aber war die Nutzung von Spolien für die Errichtung der seit dem frühen 5. Jh. immer zahlreicher werdenden Kirchen, Baptisterien und Kapellen, bei denen Bau- und Dekorationselemente der Vergangenheit in großer Zahl zum Einsatz kamen - und dies nicht nur aus rein pragmatischen Gründen, sondern zuweilen auch als symbolträchtige Signa und ideologische Bedeutungsträger, anhand derer sich die Ablösung des römisch-polytheistischen Glaubens durch das Christentum wirkungsvoll inszenieren ließ. ${ }^{304}$

ellen Schließung 346 nicht mehr regelmäßig besucht und gepflegt wurden und folglich gleichsam ,natürlich` verfielen. Ungenutzt und unansehnlich geworden, waren sie hiernach allerdings tatsächlich bevorzugte Orte bei der Suche nach geeignetem, kostenlosem Baumaterial, und wurden häufig ihrer architektonischen Bau- und Dekorationsglieder beraubt. Zum Umgang mit römischen Kultanlagen und Bildwerken in der christlichen Spätantike s. Caseau 2001; Dally 2003; und die Beiträge in den Sammelbänden Hahn 2011 und Lavan 2011.

302 Vgl. zum Folgenden Gering 2017.

303 Am eindrücklichsten lässt sich dies im italischen Raum am Beispiel städtischer domus und villae römischer Senatoren in Rom und Umgebung nachvollziehen; s. hierzu Griesbach 2010 mit dem Hinweis, dass es vor allem im 5. Jh. auch im privaten Bereich zu etlichen Kirchenstiftungen auf eigenem Grund und Boden kam. S. Guidobaldi 1999 und Machado 2012 speziell für Rom und Muntasser 2003 für Ostia. - Allgemeiner zur Wohnkultur in der Spätantike: Brands/Rutgers 1999 und die Beiträge bei Lavan 2007.

304 Zur möglichen Bedeutung von Spolien römisch-paganer Bauten als Zeichen ,christlichen Triumphalismus's. Ward-Perkins 1999; Fabricius Hansen 2003; Coates-Stephens 2003, 349f.; Fabricius Hansen 2013. 


\subsection{Wiederverwendung in gleichartigen Kontexten: Inschriftenspolien als neu errichtete Denkmäler}

Die als Baumaterial eingesetzten Inschriften waren nicht nur ihrem ursprünglichen Kontext entrissen und in vielen Fällen auch in ihrer ursprünglichen Gestalt und Materialität verändert worden. Sie hatten auch ihre eigentliche Funktion als Medien gesellschaftlicher Kommunikation und Kommemoration eingebüßt. Ein solcher Bedeutungsverlust war jedoch nicht immer vorgezeichnet, denn ältere Monumente wurden auch unter Beibehaltung ihrer ursprünglichen Bestimmung wiederverwendet. Besonders deutlich zeigt sich diese Form des Umgangs am Beispiel der in großer Zahl erneut genutzten Postamente für die Errichtung von Ehrenbildnissen und dekorativer Statuen. Zwar waren auch hier nicht die Texte, sondern vor allem die Textträger Gegenstand der Wiederverwendung - die Monumente wurden aber gerade aufgrund dieser Rolle ausgewählt und in gleicher Art und Weise wie zuvor gebraucht. Im Fall von Ehrenstatuen für Kaiser, Magistrate oder verdiente Bürger bedeutete dies, dass die alten Standbilder abgenommen oder umgearbeitet, ${ }^{305}$ die dazugehörigen Inschriften teilweise oder vollständig entfernt und die Basen mit einem neuen Text versehen wurden. Ein solches Stück begegnet etwa in einem Marmorpostament vom Forum Romanum, das seinerzeit ein Standbild Kaiser Konstantins I. trug. ${ }^{306}$ Wie es die stark bearbeitete, an manchen Stellen sehr unebene Oberfläche des Inschriftenfelds verrät, war die von einem gewissen Appius Primianus in Auftrag gegebene Inschrift zu Ehren des Kaisers aber nicht die erste und einzige auf der Basis. Offenbar hatte hier zuvor ein anderer Text gestanden, der im Zug der Wiederverwendung des Postaments für die Statue Konstantins I. ausgemeißelt und dann durch die Inschrift des 4. Jhs. ersetzt wurde. Wessen Bildnis sich dem Betrachter auf der Basis einst präsentierte, ist dem Monument zwar nicht mehr zu entnehmen, aus welcher Zeit es stammte, hingegen schon. Auf der linken Nebenseite hat sich eine nur oberflächlich entfernte Inschrift in fünf Zeilen erhalten, die das Datum der ersten Ehrung unter Kaiser Gordian im Jahr 241 noch immer zu erkennen gibt.

Zum Teil wurden Statuenbasen auch gleich mehrfach und über einen sehr langen Zeitraum hinweg wiederverwendet. So griff man etwa für ein Ensemble von Ehrenbildnissen des Kaiserhauses im tuscischen Luna gleich drei Mal auf zwei Basen republikanischer Zeit zurück.

$305 \mathrm{Zu}$ diesem Phänomen s. Varner 2004 (zu umgearbeiteten Kaiserprortraits von Augustus bis Konstantin I.); Prusac 2011 (zu kaiserlichen und privaten Porträts zwischen dem 1. und 6. Jh.).

306 CIL VI 36952 = AE 1903, 12 = LSA 1367 mit Abbildung: Domino nostro / Constantino Pio / Felici Invicto / et beatissimo / semper Augusto / filio divi Pii / Constanti Augusti / Appius Primianus v(ir) p(erfectissimus) rat(ionalis) / summae privat(ae) numini m(aiestati)q(ue) / eius dicatus // [[Ded(icata) III Id(us) Sept(embres)]] / [[d(omino) n(ostro) [---]IIII et [---] co(n)s(ulibus)]] / [[cur(antibus)]] / [[[---] IBII[---]E]] / pro magg(istris). 

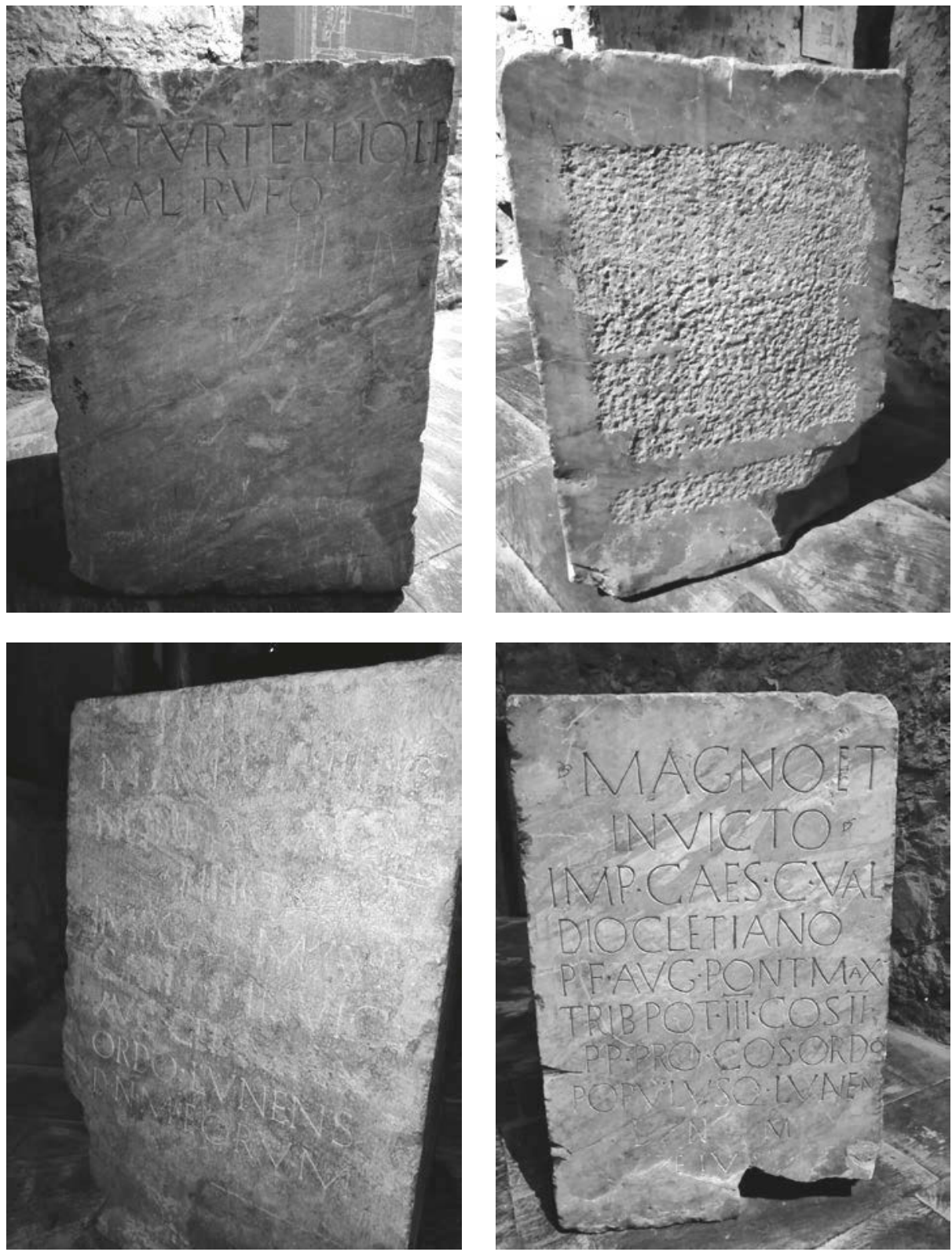

Abb. 23a-d: Mehrfach wiederverwendete Statuenbasis aus Luna (CIL XI 6956). 

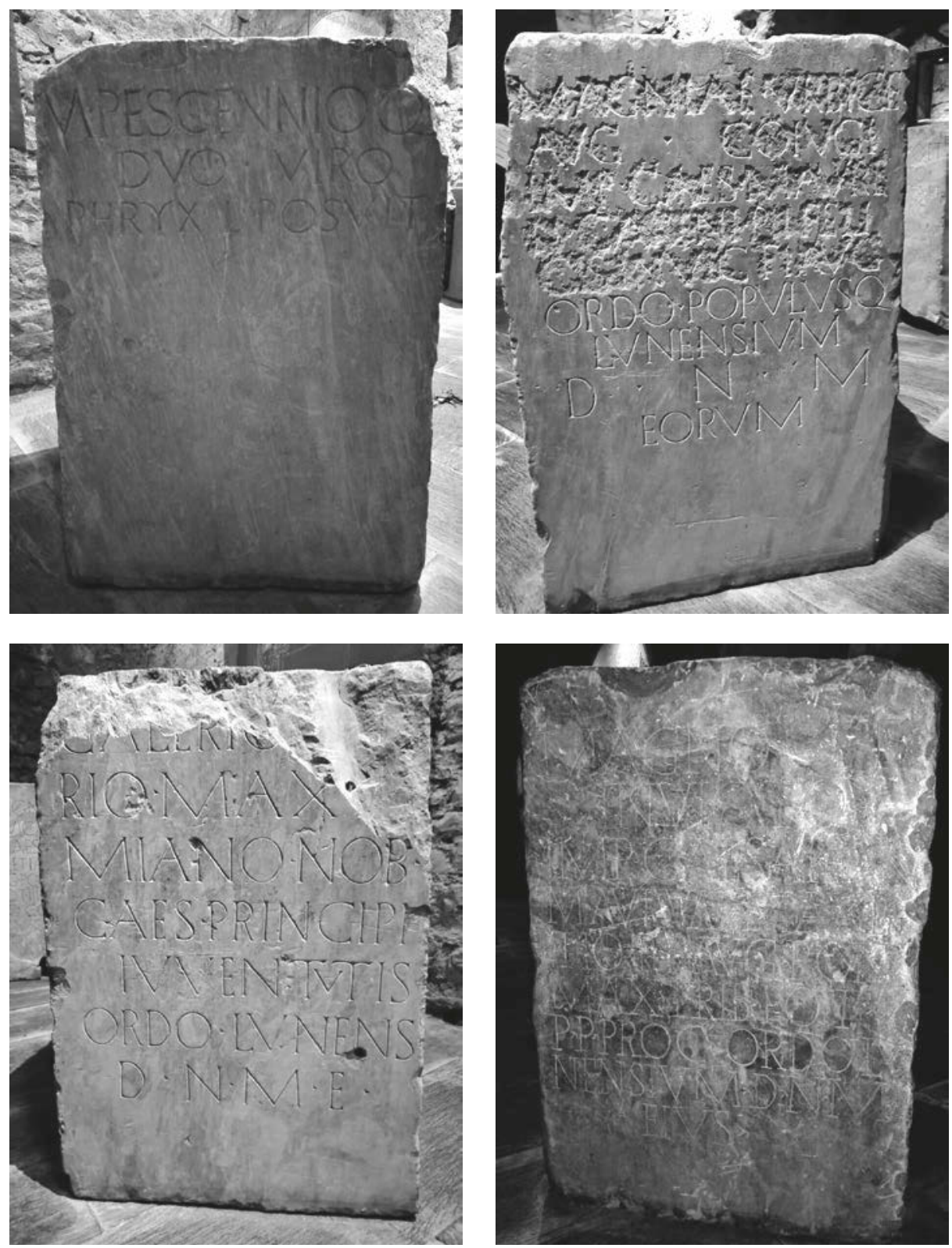

Abb. 24a-d: Mehrfach wiederverwendete Statuenbasis aus Luna (CIL XI 6957). 
Die erste Basis (Inschrift Nr.B.I.3, Abb.23a-d) war ursprünglich dem lokalen Magistraten M. Turtellius Galerius Rufus gewidmet und wurde erst mehrere hundert Jahre später für ein Ehrenbildnis Kaiser Tacitus’ wiederverwendet. Im Jahr 283 trug sie dann eine Statue des Carinus, die alsbald durch eine andere zu Ehren Diocletians ersetzt wurde. ${ }^{307}$

Ganz ähnlich erging es der zweiten Basis (Inschriften Nr. B.I.4, 5, Abb. 24a-d). Auch diese war republikanischen Ursprungs und zeigte zuerst ein Porträtbild des Quästors und duovir M. Pescennius, das ihm sein Freigelassener Phryx im 2. oder 1. Jh. v. Chr. errichtet hatte. Im späten 3. Jh. stand sie dann mit einem Bildnis der Magnia Urbica an der Seite des für ihren Gatten Carinus errichteten Denkmals, bevor sie danach zunächst für ein Standbild des Galerius, später noch einmal für Maxentius in Anspruch genommen und mit den entsprechenden Widmungen versehen wurde. ${ }^{308}$

Was mit den alten Inschriften geschah, als die entsprechenden Bildnisse an Aktualität oder Wertschätzung verloren hatten, ist ebenso interessant wie aufschlussreich: Bei beiden Basen blieben die ältesten, sehr kurzen Inschriften der republikanischen Magistrate unangetastet und sind noch heute ohne Schwierigkeiten zu lesen. Für die Anbringung der Inschriften für Tacitus bzw. Magnia Urbica hatte man die Basen augenscheinlich ganz einfach umgedreht und die Rückseite beschriftet, sodass die ersten Dedikationen vor den Augen der Betrachter verborgen blieben. Die Ehreninschrift des Tacitus wurde hingegen vollkommen entfernt, womöglich weil sie als störend oder unangemessen empfunden worden war, jetzt, da die Basis ein Bildnis des neuen Kaisers trug. ${ }^{309}$ Es ist auch nicht auszuschließen, dass die Basis zusätzlich mit weißer Farbe getüncht wurde, um die Spuren der vormaligen Benutzung zu kaschieren. Mit den beiden Inschriften des Carinus und seiner Gattin Magnia Urbica verfuhr man indes auf sehr spezielle Art und Weise. Ihrer wollte man sich im Zuge der erneuten Nutzung der Postamente entledigen, denn das Herrscherpaar war nach dem Machtantritt Diocletians in Ungnade und ihre Denkmäler der damnatio memoriae zum Opfer gefallen. Doch anstatt den kompletten Text zu eradieren, schlug man lediglich die Namen und Titulaturen der beiden aus, während man die unteren Zeilen mit der Benennung des Dedikanten - namentlich des Stadtrats der Gemeinde (ordo Lunensium) - unversehrt stehen ließ. Hier ging es also offensichtlich nicht um ästhetische Empfindungen, die das Denkmal in seiner Rolle als Bildwerk von visueller Wirkung betrafen, sondern um den konkreten Text selbst und seine Bedeutung

307 Inschrift für M. Turtellius Galerius Rufus: CIL XI 6956a; für Kaiser Tacitus: CIL XI 6956d = AE 2014, 432; für Kaiser Carinus: CIL XI 6956b; für Kaiser Diocletian: CIL XI 6956c = LSA 1617; zu dem Monument s. Mennella 2007; Angeli Bertinelli 2011, 98-101 Nr.65; Frasson 2014, $275-282$.

308 Inschrift für M. Pescennius: CIL XI 6957a; für Magnia Urbica: CIL XI 6957d; für Kaiser Galerius: CIL XI 6957c; für Kaiser Maxentius: CIL XI 6957b; zu dem Monument s. Mennella 2007; Angeli Bertinelli 2011, 101-104 Nr. 66; Frasson 2014, 282-289.

309 Von einer damnatio memoriae Kaiser Tacitus', die die Entfernung seiner Inschrift bedeutet hätte, ist jedenfalls nichts bekannt. 
als Sinnträger - wobei man durchaus zwischen verschiedenen Elementen innerhalb des Texts zu differenzieren wusste und dementsprechend auch nur diejenigen Passagen entfernte, welche die ,Geächteten' betrafen und diese gleichsam repräsentierten und vergegenwärtigten. Aus der daraus resultierenden optischen Diskrepanz zwischen eradierten und intakten Bestandteilen der Inschrift erwuchs für den Betrachter allerdings kein Konflikt, sie war im Gegenteil sogar beabsichtigt. Den Namen eines in Ungnade gefallenen Kaisers zu entfernen, bedeutete nämlich nicht, die öffentliche Erinnerung an diesen schlechthin auszulöschen und seine Existenz und frevelhaften Taten gleichsam aus der Geschichte zu streichen, sondern der Verachtung gegenüber seiner Person in einem demonstrativen Akt Ausdruck zu verleihen und das daraus hervorgegangene Monument - einstmals Zeugnis höchster Anerkennung, nunmehr Zeichen tiefster Abscheu - als Mahnmal Teil der gesellschaftlichen Wirklichkeit sein zu lassen. Der Name sollte getilgt werden, gleichwohl aber ,sichtbar abwesend“ sein. ${ }^{310}$

Die Basen aus Luna illustrieren darüber hinaus deutlich, dass es bei der Auswahl eines zur Wiederverwendung geeigneten Postaments offenbar keine Rolle spielte, für wen oder in welchem Zusammenhang es zuvor genutzt worden war. Dass die Basen einst die Bildnisse und die Namen des Carinus und der Magnia Urbica trugen und damit von Persönlichkeiten, deren Andenken kollektive Ächtung und deren Denkmäler öffentliche Schändung erfahren sollten, ließ sie in den Augen der Zeitgenossen einer abermaligen Nutzung jedenfalls nicht als unwürdig erscheinen. Womöglich war sogar genau das Gegenteil der Fall: Indem man die Basen unmittelbar im Anschluss an die Verdammung des Carnius und seiner Gemahlin für eine Ehrung seines Widersachers und neuen Augustus Diocletian bzw. dessen Caesar Galerius wiederverwendete, ließ sich einerseits der Triumph Diocletians über Carinus symbolhaft zum Ausdruck bringen und andererseits die Loyalität der Stadtgemeinde gegenüber dem regierenden Kaiser unmissverständlich demonstrieren.

Dass Statuenbasen mitunter tatsächlich bewusst, und zwar aufgrund der darauf angebrachten Inschriften ausgewählt wurden, zeigen zwei Stücke vom Forum der norditalischen Gemeinde Aquileia, die vom corrector der Provinz, Septimius Theodulus, in der Mitte des 4. Jhs. ein zweites Mal verwendet wurden. Bei dem ersten handelt es sich in der zweiten Verwendung um eine Basis für eine Statue des Hercules (Inschrift Nr. A.IV.3, Abb. 25). Auf der Oberseite sind noch die Dübellöcher für die Verzapfung des Standbilds zu erkennen, das den Heros wohl in ruhender Pose auf seine Keule gestützt zeigte. Während die recht lapidare Widmungsinschrift Sept(imius) Theodulus $v$ (ir) c(larissimus) corrector ornavit auf der mit groben Meißelschlägen von dem vormaligen titulus befreiten und geglätteten Inschriftenfläche eingeschrieben wurde,

310 G. Susini spricht in diesem Zusammenhang bewusst nicht von damnatio memoriae, sondern von memoria damnationis: Susini 1989, 872. Zum Themenkomplex der damnatio memoriae und dem Tilgen von Namen geächteter Kaiser aus öffentlichen Inschriften s. Benoist 2004; ders. 2008; Flower 2006 sowie die relevanten Beiträge in dem Sammelband Benoist 2007. 

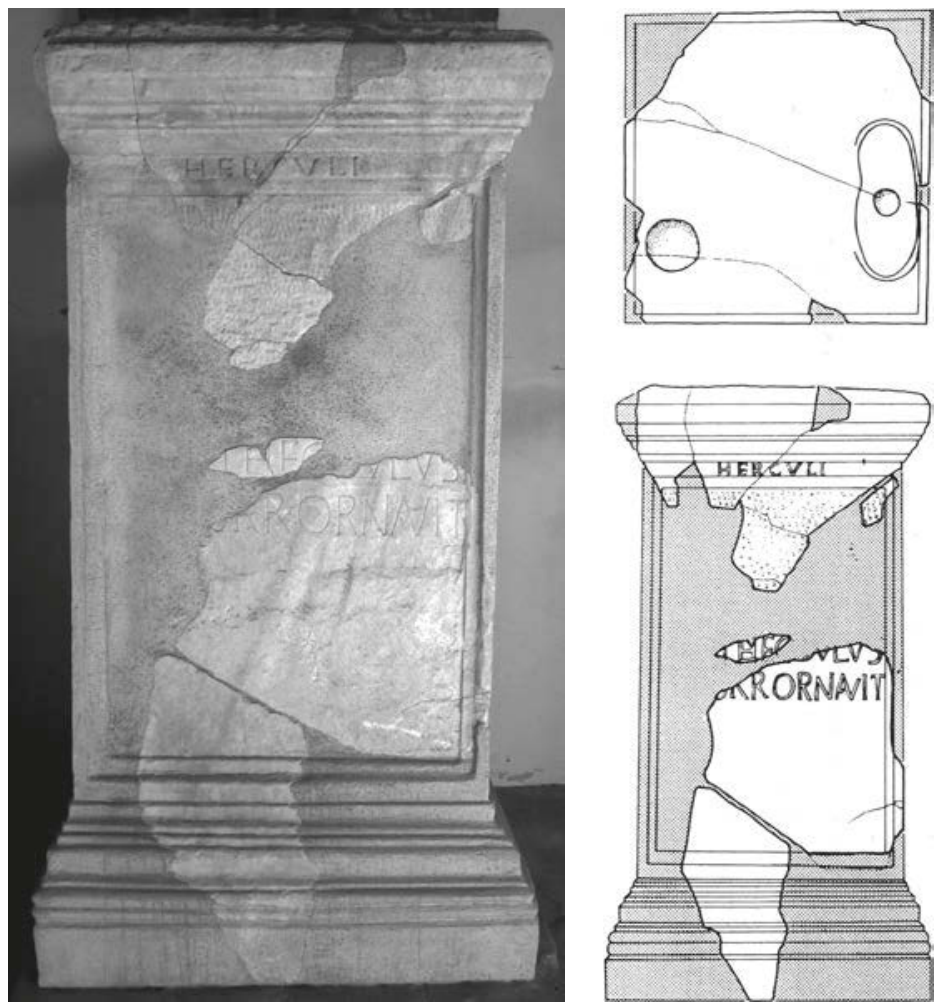

Abb. 25a-b: Wiederverwendete Statuenbasis für ein Standbild des Hercules mit der Inschrift des Septimius Theodulus, gefunden am Westrand des Forums von Aquileia.

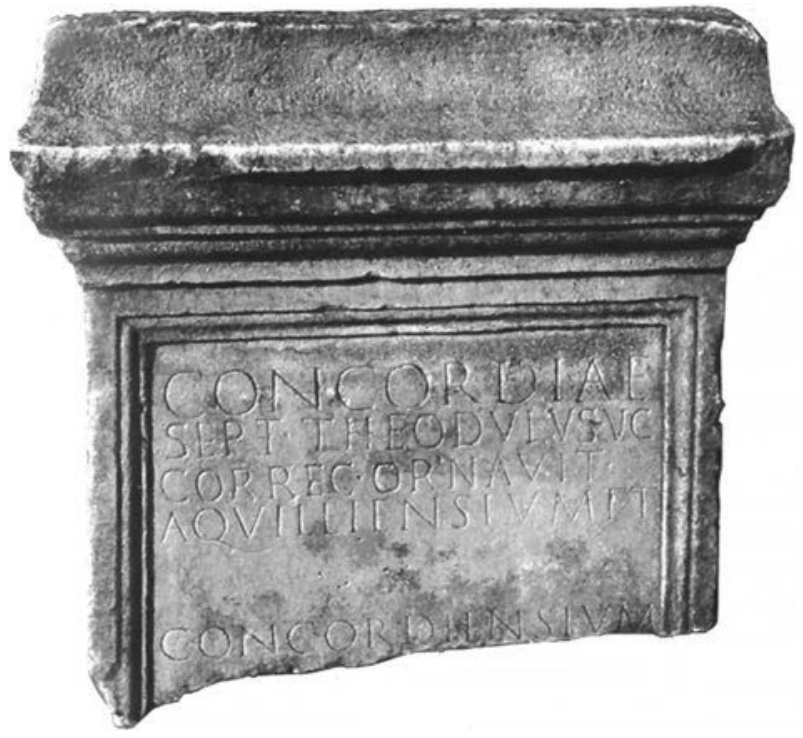

Abb. 26: Fragment einer wiederverwendeten Statuenbasis für ein Standbild der Concordia mit hinzugefügter Inschrift des Septimius Theodulus, gefunden am Westrand des Forums von Aquileia. 
stand der Name Herculi auf dem äußeren, das Feld umlaufenden Rahmen. Vermutlich stammte dieser Schriftzug noch aus der ersten Nutzungsphase der Basis und war das signum desjenigen Mannes, dem das Denkmal einst zugeeignet worden war. Im Zuge der Zweitverwendung interpretierte man es dann als Namensbezeichnung für den Heros um. ${ }^{311}$ Für eine Statue des Hercules war der Stein also wie geschaffen, trug er doch bereits den passenden Namen und verlangte nur noch danach, die alte Ehreninschrift durch den neuen Text des Theodulus zu ersetzten.

Die zweite Basis trug eine Statue der Concordia Aquileiensium et Concordiensium, also der personifizierten Eintracht zwischen den benachbarten Gemeinden Aquileia und Iulia Concordia (Inschrift Nr.A.IV.2, Abb.26). Anders als im Fall der HerculesBasis griff Theodulus die alte Inschrift auf der Frontseite mit den Worten Concordiae. Aquileiensium et Concordiensium hier allerdings vollständig auf und setzte seinen eigenen Text Sept(imius) Theodulus v(ir) c(larissimus) correc(tor) ornavit kurzerhand in den breiten Abstand zwischen den ersten beiden Zeilen der bereits vorhanden Inschrift.

Zwar ist nicht auszuschließen, dass die alte Inschrift mit weißer Farbe überdeckt war; wahrscheinlicher ist aber, dass diese sichtbar blieb, nicht zuletzt, weil die Basis ja nach wie vor eine Statue der Concordia zeigte - nun allerdings neu errichtet von Theodulus. Warum er seine Inschrift nicht einfach hinter die schon vorhandene setzen ließ, bleibt unklar. Leider ist nur der obere Teil der Basis erhalten, sodass sich nicht mehr feststellen lässt, ob im unteren Teil des Inschriftenfeldes bereits etwas anderes eingemeißelt war oder ob die kurze Inschrift des Theodulus nicht auch dort noch Platz gefunden hätte. Interessant ist die gewählte Lösung zwischen den Zeilen der alten Inschrift aber in jedem Fall, weil sie auch für den antiken Betrachter ungewohnt gewesen und bestimmt nicht immer auf den ersten Blick verstanden worden sein muss. Im Hinblick auf das Schriftbild unterscheiden sich die beiden Inschriften jedenfalls kaum. Einzig die gebrochene Haste des A verrät die spätantike Datierung der Theodulus-Inschrift, während die restlichen Buchstaben denjenigen der früheren Inschrift sehr ähneln. Womöglich hat man sogar versucht, diese nachzuahmen, um ein einheitliches Gesamtbild zu erzeugen. Um dem Betrachter das Lesen dennoch auf den ersten Blick zu ermöglichen, könnte man die beiden Inschriften mit verschiedenen Farben, etwa Rot und Schwarz, nachgemalt haben. Auch wenn die sonderbare Anordnung der Inschriften letztlich rätselhaft bleibt, bildet die Basis in jedem Fall ein eindrückliches Beispiel einer Inschriftenspolie, bei der nicht nur der Inschriftenträger, sondern auch die Inschrift Gegenstand der Wiederverwendung wurde.

311 Vgl. Zaccaria 2000, 97; ders. 2001, 486-488. 


\subsection{Wiederverwendung in ideologischen Kontexten: Inschriftenspolien als Botschaftsträger}

Während man bei der Wiederverwendung der bisher genannten Beispiele vornehmlich pragmatische Überlegungen angestellt haben wird und die mit Inschriften versehenen Basen, Postamente, Altäre und Tafeln neu geschaffenen Stücken vor allem deshalb vorgezog, weil sie einfacher, kostengünstiger und rascher $\mathrm{zu}$ beschaffen waren, konnte der Rückgriff auf ältere Monumente und Inschriften in anderen Fällen auch von ideelleren Überlegungen bestimmt sein. Jenseits ökonomischer und pragmatischer Beweggründe wurden ältere Inschriften auch konzeptuell und mit dem Ziel, eine bestimmte Botschaft auszusenden, wiederverwendet. Dabei spielten der originäre Kontext des wiederverwendeten Objekts, seine eigentliche Aufgabe und nicht zuletzt der konkrete Inhalt des darauf angebrachten Texts eine wichtige Rolle, und es waren eben diese Kriterien, die bestimmten, ob, wie, wo und wozu die Inschrift abermals zur Aufstellung gebracht wurde. Solche ideell verwendeten Inschriftenspolien funktionierten ähnlich wie Zeichen und Symbole, indem sie auf eine Person, eine Epoche, eine Handlung oder eine abstrakte Vorstellung verwiesen und diese gleichsam material repräsentierten. Zu dieser Gruppe gehören im weitesten Sinne die zuvor schon erwähnten Inschriftenbasen, bei denen der Name eines in Ungnade gefallenen Kaisers getilgt wurde und die Rasur als Sinnbild der Verachtung auch bei der abermaligen Nutzung des Monuments für einen zweiten Kaiser den Augen des Betrachters willentlich nicht entzogen wurde.

Ferner zählen dazu Denkmäler, denen wegen ihres hohen Alters, gleichsam wegen ihrer Rolle als Zeugnisse der Vergangenheit und des kulturellen Erbes eine abermalige Aufstellung zuteil wurde. Um ein Exemplar solcher Art handelt es sich offenbar bei einer kaiserzeitlichen Statue des Asklepiosknabens, welche der Finanzbeamte Aurelius Marinus im späten 3. oder frühen 4. Jh. in Rom ein zweites Mal zur Aufstellung bringen ließ. ${ }^{312}$ Das Standbild des kindlichen Gotts ist verloren, die dazugehörige Marmorbasis wurde im 17. Jh. als Spolie verbaut in der Kirche S. Martino ai Monti auf dem Esquilin entdeckt und ist heute verschollen (Abb. 27). ${ }^{313}$

Sie trägt auf drei Seiten Inschriften: Zwei längere Weihepigramme in griechischer Sprache, welche die gesamte Fläche der Front bzw. der rechten Nebenseite mitsamt dem oberen Sockel einnehmen, und einen kurzen lateinischen Text: die lapidare Inschrift des Aurelius Marinus mit den Worten Aurelius /Marinus / v(ir)p(erfectissimus) rat(ionalis) / s(ummae) $r(e i)$ auf der linken Nebenseite. Die beiden griechischen Distichen stammen noch aus dem späteren 2. Jh., als die Statue zum ersten Mal aufgestellt

312 Zur Person des Aurelius Marinus s. PLRE I Marinus 5. Er ist als Stifter einer weiteren Statue aus Rom bekannt, die möglicherweise ein Pendant zu dem Bildwerk des Asklepios bildete: CIL VI 1701a (+ S. 4738).

313 CIL VI 1701b (+ S. 4738) = CIG 5974 = IG XIV, 967 = ICUR I 102a-b; zu der Basis s. Maiuri 1912; Renberg 2006/07, 105f., 126f., cat. no. 8. 

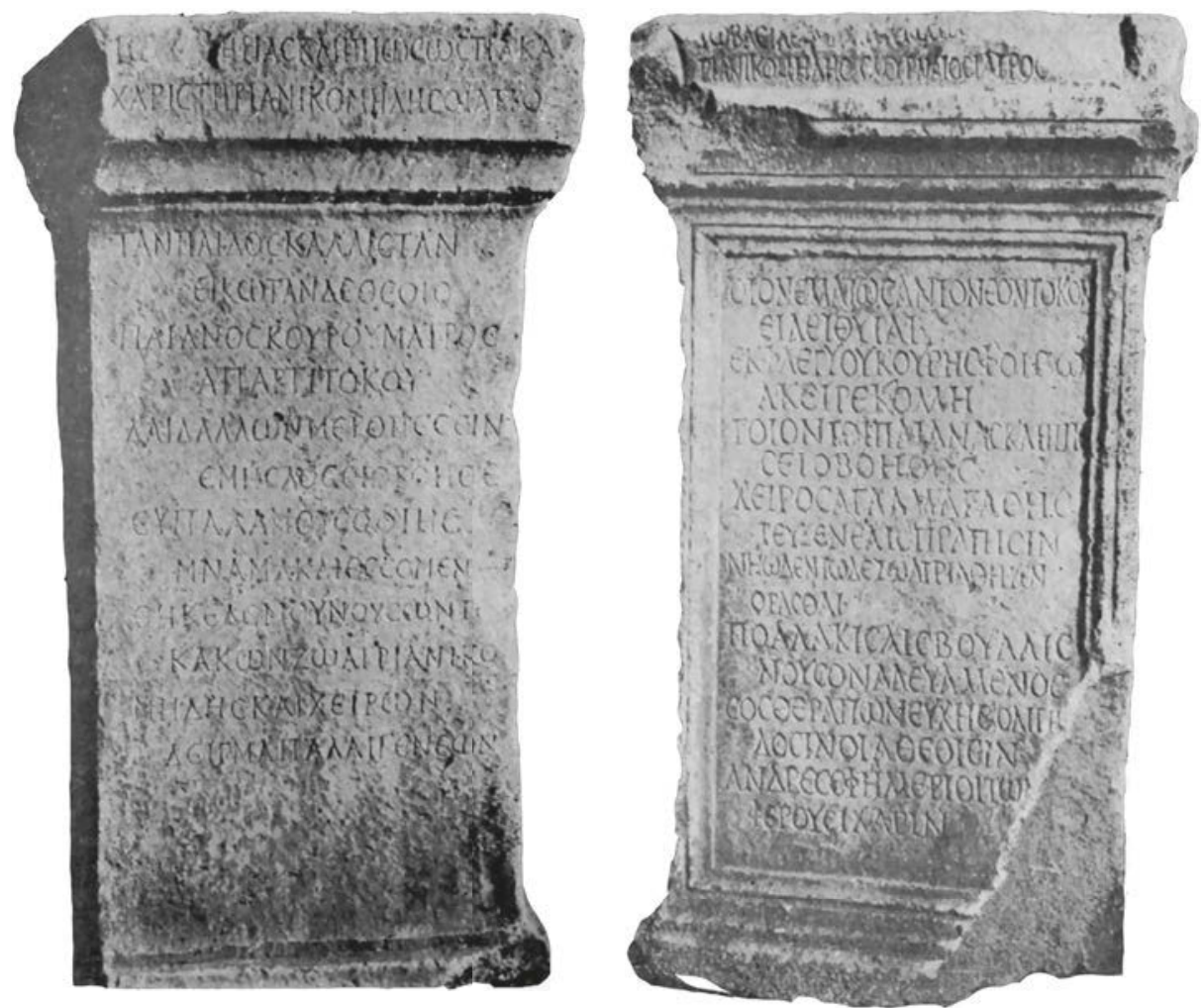

Abb. 27a-b: Wiederverwendete Statuenbasis mit griechischer Weihinschrift des Arztes Nikomedes, Rom, heute verloren, Vorder- und Nebenseite.

worden war. Wie sie berichten, war diese ein Werk des Bildhauers Boethos und von dem Arzt Nicomedes aus Smyrna als Dankesgeschenk geweiht worden. Auf der mit einem Rahmen eingefassten Frontseite hieß es: ${ }^{314}$

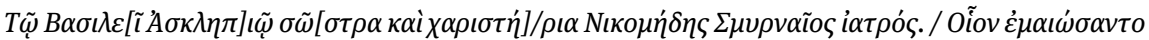

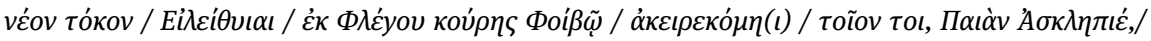

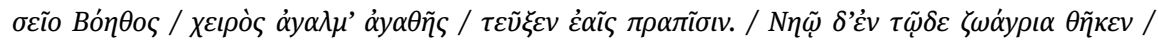

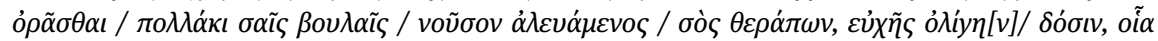

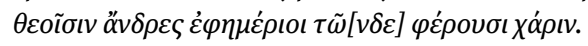

314 Die in den Editionen angegebene Bezeichnung der beiden Epigramme mit A und B ist irreführend und die bei Renberg 2006/07 vorgenommene Zuweisung des Epigramms A an die Front- bzw. des Epigramms B an die rechte Nebenseite und die daraus folgende chronologische Einordnung falsch. Bei der ursprünglichen Front kann es sich nur um die mit einem Rahmen eingefasste Seite handeln, der in der Literatur die Inschrift B zugewiesen wird. 
Dem Herrn Asklepios stellte der Arzt Nikomedes aus Smyrna, dein [d.h. Asklepios'] Jünger, der oft durch deine Ratschlüsse Krankheit abwehrte, eine Dankesweihung als sichtbaren Lohn für die Errettung aus der Gefahr in diesem Tempel auf, die geringe Gabe seines Gelöbnisses, wie sie die vergänglichen Menschen den Göttern als Dank darbringen. Wie die Eileithyien den dem ungeschorenen Apollon aus einem Mädchen der Flamme neu Geborenen schufen, so bildete ihn dir, Paianos Asklepios, Boethos, ein Weihgeschenk aus deiner [d. h. Boethos'] guten Hand, durch deren [der Hände] Verständigkeit. ${ }^{315}$

Die Inschrift der rechten Nebenseite lautete:

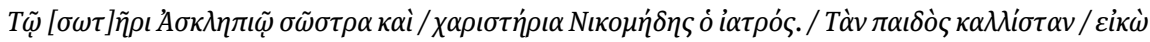

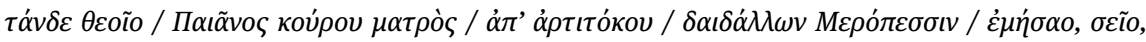

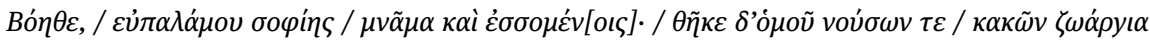

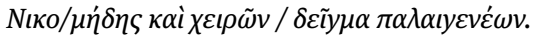

Dem Retter Asklepios stellte Nikomedes, der Arzt, als eine Dankesgabe für die Rettung aus der Gefahr und als Weihgeschenk das schönste Bildnis des Knaben auf, das (Bildnis) des Gottes Paianos, als Knabe gerade erst aus der Mutter geboren, welches du kunstfertig schufst, ein Zeugnis, Boethos, deiner kunstvollen Weisheit. Und für die Menschen hat es Nikomedes aufgestellt, als Lohn für die Errettung aus Krankheit und Übel und als Beweis der uralten [d.h. der göttlichen] Hände.

Der aus Kleinasien stammende Nikomedes war womöglich der aus einer Grabinschrift bekannte Arzt gleichen Namens, der im späteren 2. Jh. in Rom wirkte. ${ }^{316}$ Mit dem Bildhauer Boethos könnte der berühmte Künstler des 2. Jhs. v. Chr. aus Kalchedon oder der in Athen tätige Sohn des Diodotos gemeint sein, was allerdings nicht zwangsläufig bedeuten muss, dass die Asklepios-Statue tatsächlich ein griechisches Original war. Womöglich hatte Nikomedes auch ,nur' eine römische Kopie nach einem Vorbild des Boethos erstanden. ${ }^{317}$ Wie es in der ersten Inschrift heißt, hatte er sie in einem dem Gott geweihten Tempel aufgestellt, bei dem es sich wohl um denjenigen des AsklepiosHeiligtums in der Nähe der Trajans-Thermen handelte. ${ }^{318}$ Warum die Basis gleich zwei (nicht wörtlich, aber inhaltlich nahezu identische) Weihepigramme trägt, ist unklar. Angesichts der unterschiedlichen Schriftgestaltung, die an zwei verschiedene Steinmetze denken lässt, und dem leicht abgeänderten Text der Nebenseite, in dem der Tempel als Aufstellungsort nicht mehr erwähnt ist, könnte man sich vorstellen, dass

315 Das Epigramm könnte sich an ein Vorbild aus Griechenland anlehnen, das Nikomedes dort einst selbst gesehen hat. Die beiden Gedichte der Asklepios-Statue aus Rom sind allerdings von eher bescheidenem literarischem Wert und wahrscheinlich keine direkten Rezitationen von griechischen Weihinschriften hellenistischer Zeit.

316 CIG 6265 = IG XIV 1879. Zur Person des Nikomedes s. RE 17,1, 1936, Sp. 500 s. v. Nikomedes 14 (F. Kliem).

317 Zur Person des Boethos und der Frage nach Original oder Kopie s. Vollkommer I, 2001, 120f. s.v. Boethos (V) mit weiteren Literaturverweisen.

318 Vgl. Renberg 2006/07, 105-108. 
die Statue, nachdem sie zuerst im Inneren des Tempels aufgestellt worden war, an einen anderen Ort im Heiligtum verbracht und im Zuge dieser Versetzung abermals geweiht und mit der zweiten Inschrift auf der Nebenseite ausgestattet wurde.

Was auch immer Nikomedes dazu veranlasste, sein Weihgeschenk erneut mit einer Inschrift zu versehen - fest steht, dass sich Aurelius Marinus rund 100 Jahre später des Stücks bediente und es erneut zur Aufstellung brachte, womöglich in seiner Rolle als kaiserlicher Beamte und anlässlich der Renovierung des Heiligtums durch Diocletian im Jahr 303. ${ }^{319}$ Warum er ausgerechnet die alte Statue des Boethos samt der dazugehörigen Inschriftenbasis auswählte und die Widmungen des Nikomedes vollkommen unberührt auf dem Monument stehen ließ, anstatt ein neues Bild des Gottes - oder wenigstens eine neue Basis - aufzustellen, ist leicht verständlich, wenn man sich die Funktion wiederverwendeter Denkmäler als absichtsvoll inszenierte Bedeutungsträger vergegenwärtigt. Die beiden griechischen Epigramme bekundeten, dass es sich bei der Statue um ein (vermeintlich) griechisches Original handelte und als solches um ein Bildwerk, das mit römischen Augen betrachtet den Nimbus großer Kunstfertigkeit und Ehrwürdigkeit trug. Über ein solches Stück zu verfügen und öffentlich aufzustellen, bedeutete soziale Anerkennung. Wahrscheinlich wird Aurelius dafür gesorgt haben, dass alle drei beschrifteten Seiten der Basis uneingeschränkt zu sehen waren, dass der Betrachter also nicht nur seine eigene Inschrift, sondern auch die beiden griechischen Epigramme vor Augen hatte, wenn er dem Bildwerk gegenübertrat. Dass die griechischen Verse so manchen Betrachter werden ratlos zurückgelassen haben, weil er der griechischen Sprache, geschweige denn der griechischen Dichtkunst nicht mächtig war, sollte Aurelius im Übrigen nicht allzu sehr gekümmert haben. Auch wer die Texte nicht lesen und verstehen konnte, wusste die Statue aufgrund des fremden Alphabets als griechisches Kunstwerk zu erkennen und die (zumindest propagierte) Kunstbeflissenheit des Aurelius - dessen Name nunmehr leicht verständlich in der prägnanten lateinischen Inschrift auszumachen war - zu erahnen. Keine noch so literarisch anspruchsvolle lateinische Inschrift hätte eine gleichwertige Wirkung auf den Betrachter ausüben und den gleichen Effekt erzielen können wie es die älteren, in griechischen Lettern abgefassten Epigramme vermochten, zumal diese ihr Potential gleich auf zweifache Weise entfalteten. Denn sie sprachen den rezipierenden wie den perzipierenden Betrachter gleichermaßen an: hier den Lesenden auf der inhaltlichen Ebene des Texts und dort den Schauenden auf der visuellen Ebene der Schrift.

Am Beispiel der Asklepios-Basis lässt sich auf der einen Seite nachvollziehen, wie und wozu inschriftliche Denkmäler wiederverwendet werden konnten, angefangen bei der abermaligen Beschriftung durch Nikomedes, der Neuerrichtung durch Aurelius bis hin zur Umnutzung als Baumaterial in der Kirche S. Martino ai Monti. Auf

319 Wie es aus der anonymen Passio SS. Quattuor Coronatorum des späten 6. oder frühen 7. Jhs. (Acta Sanct., Nov. III) hervorgeht, ließ Diocletian das Heiligtum während eines Besuchs in Rom anlässlich der Feierlichkeiten zu seinen vicennalia 303 renovieren; s. hierzu Renberg 2006/07, 105. 
der anderen Seite offenbart es eine vergleichsweise seltene, dafür aber umso wirkungsvollere Form der Wiederverwendung, bei der ältere Denkmäler als antiquarische Kunstschätze zur Steigerung des sozialen Prestiges abermals zur Aufstellung gebracht wurden. Die originären Inschriften aus der Zeit der ersten Errichtung übernahmen dabei eine zentrale Aufgabe, waren sogar von entscheidender Bedeutung für die Effektivität des Stücks in seiner Rolle als wiedererrichtetes Denkmal, denn sie authentifizierten es als wertvolles Bildwerk von hohem Alter und nobler Herkunft und verliehen ihm mithin eben genau jene Qualitäten, welche bei den römischen Rezipienten mit besonderer Wertschätzung verbunden waren.

Jenseits solcher antiquarischer Inszenierungen älterer Monumente spielte in anderen Zusammenhängen weniger das Alter oder der kulturelleStellenwert einer wiederverwendeten Inschrift eine Rolle als vielmehr deren Bedeutung als Repräsentant und Sinnbild eines bestimmten Wertesystems oder einer bestimmten Person. In der Spätantike begegnet diese Spielart der Wiederverwendung vor allem in religiös-christlichen Kontexten und hier besonders in Verbindung mit Kirchenbauten: Gemeint sind ehemals als öffentliche Denkmäler aufgestellte Inschriften, die als Baumaterial und Pflastersteine in frühchristlichen Kirchenanlagen verbaut wurden - und dies keineswegs nur aus ökonomischen und pragmatischen Beweggründen, sondern mit durchaus ideologischer Aussageabsicht. Das sog. Weiße Kloster bei Sohag in Oberägypten aus dem 5. Jh. etwa bietet ein einprägsames Beispiel dieser Art: Für das Bodenpflaster im östlichen Teil des zentralen Mittelschiffs hatte man auf eine große Platte aus Assuan-Granit zurückgegriffen, auf der noch heute Spuren ägyptischer Hieroglyphen zu sehen sind. ${ }^{320}$ Anstatt die Schriftzeichen zu entfernen, indem man sie ausmeißelte, oder sie zu verbergen, indem man die Platte umdrehte, hatte man sich anscheinend ganz bewusst dazu entschieden, die Hieroglyphen dem Kirchenbesucher offen sichtbar zu präsentieren, und dies zudem an einer sehr prominenten Stelle im Kirchenboden, die den Prozessionsweg vom Eingang in Richtung des Allerheiligsten markierte. Die damit verbundene Botschaft war unmissverständlich: Das Christentum ist zum Sieger über das ,Heidentum‘ geworden. Die Hieroglyphen-Tafeln waren also zu ausdrucksstarken Symbolen des heidnischen Glaubens an die alten Götter Ägyptens erklärt und so in den Boden des Gotteshauses eingelassenen worden, dass sie von den Gläubigen im wahrsten Sinne des Worts ,mit Füßen getreten“ wurden, was letzten Endes nichts weniger als einer absichtsvollen Entweihung gleichkam. ${ }^{321}$

Dass es die Praxis, Spolien paganer Bauwerke und Denkmäler in herabwürdigender Weise für die Pflasterung des Bodens zu verwenden, tatsächlich gegeben haben muss, legt eine Episode bei Marcus Diaconus aus dem 5. Jh. nahe. In seiner Vita sancti Porphyrii berichtet er über die Zerstörung des Marnas-Tempels in Gaza durch Bischof Porphyrius:

320 Monneret de Villard 1925.

321 Vgl. Deichmann 1975, 59. 
Nachdem die Asche vergraben und aller Unrat beseitigt worden war, befahl der heilige Bischof, die übriggebliebenen Trümmer der Marmorverkleidung des Marneions, von denen es hieß, dass sie heilig seien und sich an einem - besonders Frauen - unzugänglichen Ort befänden, diese also auf dem Platz außen vor dem Heiligtum auszulegen, damit sie nicht nur von Männern mit Füßen getreten würden, sondern auch von Frauen, Hunden, Schweinen und wilden Tieren. ${ }^{322}$

Die Wirkung dieser Tat muss enorm gewesen sein, denn Marcus Diaconus fährt fort: „Das schmerzte die Götzendiener noch mehr als der Brand des Tempels. Daher treten die meisten von ihnen, besonders die Frauen, bis heute nicht auf diese Marmorplatten." Und nicht zuletzt wird die hohe Bedeutung der symbolischen Entweihung durch rituelles Betreten auch aus einem kaiserlichen Erlass des Jahrs 427 deutlich - nunmehr allerdings aus der entgegengesetzten Perspektive betrachtet. Darin heißt es, dass sich niemand unterfangen solle, „das Zeichen des Erlösers Christus, möge es in Stein oder Marmor gehauen oder darauf aufgemalt sein, zu ebener Erde anzubringen“, damit dieses nicht durch das Betreten der Kirchenbesucher geschändet würde. ${ }^{323}$

Außerhalb der Grenzen Nordafricas und des vorderen Orients sind Zeugnisse dieser Art wesentlich seltener zu finden. Inschriftenspolien als Symbole ,christlichen Triumphalismus' einzusetzen scheint in erster Linie eine im östlichen Christentum verbreitete Sitte gewesen zu sein, die im Westen des Reichs keine nennenswerte Verbreitung gefunden hat. Jedenfalls sind Belege hierfür nur schwer auszumachen und auch in unserem Untersuchungsgebiet des italischen Raums rar. Bei drei in frühchristlichen Kirchenanlagen Roms wiederverwendeten Inschriftensteinen liegt jedoch die Vermutung nahe, dass auch diese einst als konzeptuelle Bedeutungsträger eingesetzt wurden. Dabei geht es um je einen Stein mit dem Namen Diocletians in den Kirchen SS. Alessio e Bonifacio auf dem Aventin und in S. Pancrazio in Monte Verde ${ }^{324}$ sowie um das Bruchstück einer Tafel in S. Constanza an der Via Nomentana, welche ehemals zu einem Ehrendenkmal Maximians gehörte. ${ }^{325}$ Zumindest im Fall der Diocletians-

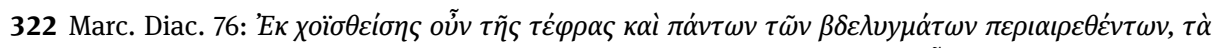

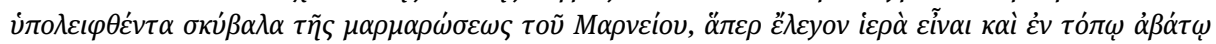

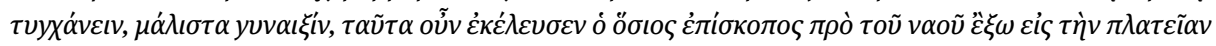

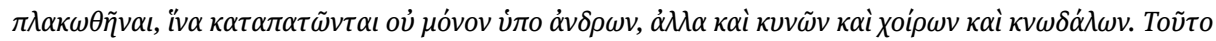

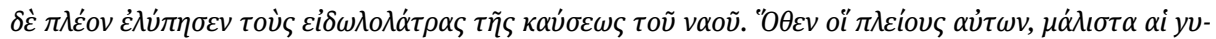

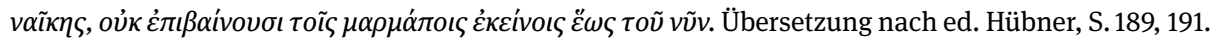
323 Cod. Iust. 1,8: Cum sit nobis cura diligens per omnia Superni Numins religionem tueri, signum Salvatoris Christi nemini licere vel in solo vel in silice vel in marmoribus humi positis insculpere vel pingere, sed quodcumque reperitur tolli, gravissima poena multando eo qui contrarium statutis nostris tentaverit, specialiter imperamus. Übersetzung nach G. Härtel/F.-M. Kaufmann (Hgg.), Codex Justinianus, Leipzig 1991, 40f.

324 Santi Alessio e Bonifacio: CIL VI 1131a (+ S. 4327); Lanciani 1988, 33; S. Pancrazio in Monte Verde: Armellini 1942, Bd. II, 1186. Die beiden Stücke sind heute verloren.

325 CIL VI 1129 mit Abbildung bei: http://edh-www.adw.uni-heidelberg.de/edh/foto/F010587.JPG (Stand: 3.5.2019). 
Inschrift in SS. Allessio e Bonifacio wissen wir, dass diese in der Schwelle des Eingangsportals platziert war, und damit an einem Ort, der den Übergang vom Profanen zum Heiligen markierte und der von jedem Besucher der Kirche unwillkürlich überschritten werden musste. ${ }^{326}$ Vor dem historischen Hintergrund der Christenverfolgungen unter Diocletian und seinen Mitregenten und des anschließenden Siegeszuges des neuen Glaubens seit konstantinischer Zeit ließen sich auch diese Spolien als absichtsvoll eingesetzte und gezielt positionierte Repräsentanten verstehen, welche die ,heidnischen‘ Kaiser selbst vergegenwärtigen sollten. Die Inschriftensteine überschreitend, traten die Gläubigen den durch seinen Namen vergegenwärtigten Kaiser nun buchstäblich mit Füßen, würdigten den verhassten Peiniger durch diesen rituellen Akt herab und übten sinnbildlich Vergeltung an ihm. ${ }^{327}$ Dabei war es vermutlich nicht einmal notwendig, dass der Besucher die Inschriften beim Betreten der Kirche tatsächlich zur Kenntnis nehmen konnte. Ob die Tafeln mit der Schriftseite nach unten oder nach oben im Boden verlegt waren, spielte für die Effektivität des Rituals keine entscheidende Rolle. Denn der Akt des Mit-Füßen-Tretens vollzog sich so oder so, gleichgültig, ob es die Kirchenbesucher wissentlich und willentlich taten oder nicht. Womöglich war die Orientierung der Inschriften in Richtung des Bodens sogar die bedeutsamere und erfüllte vielleicht den gleichen Sinn wie die christliche Sitte, pagane Bildwerke mit dem Gesicht nach unten in der Erde zu vergraben, wie es etwa von Statuen aus Athen und Aphrodisias überliefert ist. ${ }^{328}$ Es war dies eine Demonstration von Abscheu, deren Bedeutung auch im Fall der mit ihrer Beschriftung nach unten verlegten Inschriftenspolien zum Tragen gekommen sein könnte und die dem ostentativen Mit-Füßen-Treten im Fall der sichtbaren Namenszüge in ihrer Wirkung in nichts nachgestanden hätte.

326 Nerini 1752, 360. Der Anbringungsort der beiden anderen Stücke ist nicht mehr zu ermitteln.

327 Vgl. Coates-Stephens 2002, 292. Ähnlich Moralee 2006 am Beispiel der frühchristlichen Märtyrerkirche S. Theodor in Gerasa. Hier wurde der Triumph des Christentums nicht nur durch neu geschaffene Inschriften über den Ein- bzw. Ausgängen der Kirche zum Ausdruck gebracht, sondern - so Moralee - auch durch die gezielte Spoliierung kaiserzeitlicher Inschriften in den Fundamenten und Wänden. Dieser Befund ist allerdings insofern problematisch, als dass der Inschriftentext dabei offenbar keine Rolle spielte, einige Inschriften jedenfalls ohne Berücksichtigung der Schrift zerschnitten oder mit der Schrift nach unten verbaut wurden. Um die Inszenierung der Stücke kann es also kaum gegangen sein. Eine weniger radikale Erklärung bestünde darin, die Inschriftenspolien nicht als Symbole des christlichen Triumphs, sondern als Zeichen der langen Kulttradition an diesem Ort zu begreifen, nicht zuletzt, weil viele der wiederverwendeten Inschriften von den hier zuvor liegenden paganen Heiligtümern zu stammen scheinen. So gesehen, würde sich auch die Annahme relativieren, die frühen Christen hätten pagane Tempel absichtlich zerstört und dann für die Errichtung von Kirchenbauten ausgeschlachtet; vgl. hierzu oben Anm.301. Dass dies auch am archäologischen Befund in wenigsten Fällen abzulesen ist, betonte zuletzt mit Blick auf Ägypten Dijkstra 2011.

328 Zur rituellen Vergrabung paganer Bildwerke mit dem Gesicht zur Erde s. Caseau 2001, 112-116. 


\subsection{Zusammenfassung}

Wie man in der Spätantike mit älteren Monumenten und ihren Inschriften umging, welcher Stücken man sich bediente, auf welche Art und Weise man sie abermals verwendete und welche Absichten man damit verfolgte, war angesichts der vielen verschiedenen Befunde disparat. Die Praxis der Wiederverwendung lässt sich daher kaum als ein einheitliches, homogenes Phänomen beschreiben und noch weniger als ein solches bewerten. Statt von ,Praxis“ müsste man ehrlicherweise von ,Praktiken“ sprechen, die sich in vielgestaltiger und schillernder Weise Ausdruck verschafften. So konnte sowohl der Textträger als auch der Text zum Gegenstand der Wiederverwendung gemacht werden. Pragmatische Beweggründe mochten ebenso eine Rolle gespielt haben wie ideelle. Die Inschriften wurden im Zuge ihrer abermaligen Nutzung ignoriert, kaschiert, eliminiert, integriert und regelrecht inszeniert. Und schließlich war die körperlich erfahrbare Präsenz eines Texts auch bei dessen absichtsvoller Wiederverwendung nicht immer notwendig, sondern wurde unter Umständen sogar bewusst in Kauf genommen oder gar vermieden. Auch wenn zu allen Zeiten Wiederverwendung praktiziert wurde, so in der Spätantike doch in einer neuen Intensität, für die nicht zuletzt die strenge Gesetzgebung jener Zeit Verantwortung trug, die den Rückgriff auf ältere Monumente forcierte. Richten wir den Blick hingegen nicht zurück, sondern nach vorne, so zeigt sich, dass das Phänomen im frühen und vor allem im hohen Mittelalter noch einmal zusätzliche Schubkraft erfuhr und sich insbesondere in der mannigfachen Verwendung antiker Architekturspolien für den Bau von Kathedralen nierderschlug. ${ }^{329}$ Es geschah im Übrigen auch erst jetzt, dass antike Inschriften aus vornehmlich ästhetischen Gründen, nämlich als visuell ansprechende, in ihrer Erscheinungsform als kunstvoll, stilvoll oder ganz einfach ,schön` empfundene Artefakte ein neues Dasein als Spolien führten. In diesem Sinn griff man etwa im 15. Jh. auf die schon damals berühmten Epigramm-Inschriften des Damasus zurück, zerschnitt die Tafeln zu geometrischen Stücken und integrierte sie in Kosmaten-Fußböden, wie etwain denjenigen der Lateran-Basilika in Rom. ${ }^{330}$ In der Spätantikescheint es diese Art der ästhetisch motivierten Wiederverwendung indes nicht gegeben zu haben - jedenfalls nicht in substantieller Form. Zwar finden sich im Bereich des privaten Wohnens hier und da Inschriftenspolien, die scheinbar bewusst als Dekorationselemente eingesetzt wurden, wie etwa in der sog. Domus del Protiro in Ostia, wo Grabinschriften aus weißem Marmor als Abflussdeckel im Boden fungierten. ${ }^{331}$ Doch können wir uns hier genau wie in den meisten Fällen vergleichbarer Art - nicht sicher sein, es tatsächlich mit dem Werk des spätantiken Hausherren zu tun zu haben oder nicht doch mit dem Resultat modernen Restaurierungseifers, bei dem unsere heutigen ästhetischen Wertvorstellungen auf die Lebensrealität der Spätantike übertragen wurde.

329 S. hierzu zum Beispiel Poeschke 1996; D’Onofrio 2003; Esch 2005; Binding 2007.

330 ICUR VII 19932.

331 Boersma 1985, 291-293; Danner 2017, 263. 
